Australian

National

University

Crawford School of Public Policy

\title{
CAMA
}

Centre for Applied Macroeconomic Analysis

\section{Are Fiscal Multipliers Estimated with Proxy-SVARs Robust?}

\section{CAMA Working Paper 69/2020 July 2020}

Giovanni Angelini

University of Bologna

Giovanni Caggiano

Monash University

University of Padova

Centre for Applied Macroeconomic Analysis, ANU

\section{Efrem Castelnuovo}

University of Melbourne

University of Padova

Centre for Applied Macroeconomic Analysis, ANU

\section{Luca Fanelli}

University of Bologna 


\section{Abstract}

How large are government spending and tax multipliers? The fiscal proxy- SVAR literature provides heterogenous estimates, depending on which proxies - fiscal or non-fiscal - are used to identify fiscal shocks. We reconcile the existing estimates via a flexible vector autoregressive model that allows to achieve identification in presence of a number of structural shocks larger than that of the available instruments. Our two main findings are the following. First, the estimate of the tax multiplier is sensitive to the assumption of orthogonality between total factor productivity (non-fiscal proxy) and tax shocks. If this correlation is assumed to be zero, the tax multiplier is found to be around one. If such correlation is non-zero, as supported by our empirical evidence, we find a tax multiplier three times as large. Second, we find the spending multiplier to be robustly larger than one across different models that feature different sets of instruments. Our results are robust to the joint employment of different fiscal and non-fiscal instruments.

\section{Keywords}

Fiscal multipliers, fiscal policy, identification, instruments, structural vector autoregressions.

\section{JEL Classification}

C52, E62

\section{Address for correspondence:}

(E) cama.admin@anu.edu.au

\section{ISSN 2206-0332}

The Centre for Applied Macroeconomic Analysis in the Crawford School of Public Policy has been established to build strong links between professional macroeconomists. It provides a forum for quality macroeconomic research and discussion of policy issues between academia, government and the private sector.

The Crawford School of Public Policy is the Australian National University's public policy school, serving and influencing Australia, Asia and the Pacific through advanced policy research, graduate and executive education, and policy impact. 


\title{
Are Fiscal Multipliers Estimated with Proxy-SVARs Robust?*
}

\author{
Giovanni Angelini \\ University of Bologna \\ Giovanni Caggiano \\ Monash University \\ University of Padova \\ Centre for Applied Macroeconomic Analysis \\ Efrem Castelnuovo \\ University of Melbourne \\ University of Padova \\ Centre for Applied Macroeconomic Analysis \\ Luca Fanelli \\ University of Bologna
}

June 2020

\begin{abstract}
How large are government spending and tax multipliers? The fiscal proxySVAR literature provides heterogenous estimates, depending on which proxies fiscal or non-fiscal - are used to identify fiscal shocks. We reconcile the existing estimates via a flexible vector autoregressive model that allows to achieve identification in presence of a number of structural shocks larger than that of the available

*We thank Ralf Brüggeman, Dario Caldara, Fabio Canova, Giovanni Pellegrino, Pedro GomisPorqueras, Bruce Preston, Søren Hove Ravn, Antti Ripatti, Xuan Zhou, and participants at seminars held at the Universities of Bologna, Helsinki, Adelaide, Deakin University, and the 30th EC Conference $^{2}$ on "Identification in Macroeconomics" (Oxford University) for useful feedback, and Valerie Ramey and Sarah Zubairy for an email exchange on a fiscal proxy available on Ramey's website. Giovanni Angelini thanks the University of Melbourne (where part of this research was developed) for its kind hospitality. Financial support by the Australian Research Council via the Discovery Grant DP160102281 is gratefully acknowledged. Corresponding author: Efrem Castelnuovo, efrem.castelnuovo@gmail.com .
\end{abstract}


instruments. Our two main findings are the following. First, the estimate of the tax multiplier is sensitive to the assumption of orthogonality between total factor productivity (non-fiscal proxy) and tax shocks. If this correlation is assumed to be zero, the tax multiplier is found to be around one. If such correlation is nonzero, as supported by our empirical evidence, we find a tax multiplier three times as large. Second, we find the spending multiplier to be robustly larger than one across different models that feature different sets of instruments. Our results are robust to the joint employment of different fiscal and non-fiscal instruments.

Keywords: Fiscal multipliers, fiscal policy, identification, instruments, structural vector autoregressions.

JEL codes: C52, E62. 


\section{Introduction}

The COVID-19 shock is predicted to generate a sizeable recession in the US and around the world (International Monetary Fund (2020)). While an immediate response by fiscal (as well as monetary) policymakers has been implemented, other interventions to sustain aggregate demand are likely to be needed in the remainder of 2020 and the following years. Such interventions should be designed on the basis of assumptions on the fiscal multipliers, whose quantification is a difficult task. The reason is that spending and tax revenues are in large part endogenous, and tackling this endogeneity issue to identify the output effects of exogenous variations in fiscal variables - i.e., fiscal shocks - is challenging.

One way to identify causal effects that has recently gained a lot of traction is the "proxy-SVAR" (or "SVAR-IV") approach, which relies on the use of instruments for the identification of the shocks of interest (see Stock and Watson (2012) and Mertens and Ravn (2013) for early contributions, and Stock and Watson (2018) for a review). ${ }^{1}$ Using a measure of unanticipated exogenous variations in tax revenues constructed via a narrative approach, Romer and Romer (2010) and Mertens and Ravn (2011b, 2012, 2013, 2014) find tax multipliers between 2 and $3 .^{2}$ Differently, Caldara and Kamps (2017) employ Fernald's (2014) measure of total factor productivity (TFP) to identify exogenous changes of output in fiscal policy rules. Conditional on these rules, they recover the fiscal policy shocks of interest and their business cycle effects. Their estimates of the tax multiplier range between 0.5 and 0.7 , while that of the spending multiplier is 1-1.3. While Caldara and Kamps' (2017) estimates of the tax multiplier are substantially smaller than those provided by the papers mentioned above, those of the spending multiplier are larger than the ones documented in the papers surveyed by Ramey (2019), which point to a 0.6-1 range. In light of policymakers' need to get reliable and robust indications on the size and relative strength of the spending and tax multipliers, the heterogeneity of the estimates provided by the extant literature is problematic.

Contributions of our paper. This paper employs both fiscal and non-fiscal in-

\footnotetext{
${ }^{1}$ We will use the terms "instruments" and "proxies" interchangeably throughout the paper.

${ }^{2}$ Lower figures are obtained by Favero and Giavazzi (2012), who estimate a tax multiplier similar to Blanchard and Perotti's (2002), and Perotti (2012), who finds a tax multiplier larger than Blanchard and Perotti's (2002) but smaller that those documented in the text. For a discussion on the reasons behind the discrepancies between Mertens and Ravn's set of estimates, Favero and Giavazzi's, and Perotti's, see Mertens and Ravn (2014).
} 
struments in a proxy-SVAR setting and makes two contributions to the literature. First, we show that the assumption of orthogonality (exogeneity) between the non fiscal proxy (TFP as in Caldara and Kamps (2017)) and the tax shocks is key in determining the size of the tax multiplier. If we entertain this assumption, we get tax multipliers in the range of 0.5 and 0.7. Differently, if the orthogonality condition is relaxed (something we can do in our multivariate framework), the data: i) point to a negative and significant correlation between TFP and tax shocks; ii) imply a tax multiplier larger than 3. Second, we find a fiscal spending multiplier larger than one. This estimate is very robust to the use of different instruments and modeling specifications.

Methodology. We obtain these results by working with a flexible proxy-SVAR methodology recently proposed by Angelini and Fanelli (2019) and termed "augmented and constrained SVAR" (AC-SVAR). In short, the AC-SVAR jointly models both the variables of interest (e.g., fiscal spending, tax revenues, and output) and the proxies used to identify the shocks of interest. This approach has three main advantages over alternatives fiscal proxy-SVARs. First, it enables us to trade relatively uncontroversial zero restrictions (e.g., the zero contemporaneous response of fiscal spending to output as in Blanchard and Perotti (2002), or the zero response of tax revenues to fiscal spending shocks as in Caldara and Kamps (2017)) with the possibility of instrumenting more than one shock with one proxy. ${ }^{3}$ This is of particular importance in our analysis, as it allows us to unveil the negative correlation between the TFP proxy and the tax shocks in the data and, consequently, to reconcile the different estimates of the tax multiplier obtained in the literature. Second, our approach easily accommodates the case in which multiple instruments are used to identify multiple shocks. Third, it enables us to test the validity of the proxy-SVAR specification (validity of instruments included) without resorting to information outside the VAR framework at work.

Instruments. Our baseline exercises are conducted by using three different instruments. The first one is the unanticipated tax shocks proposed by Mertens and Ravn (2011b). They isolate the unanticipated component of the tax shocks series originally constructed by Romer and Romer (2010), who identify exogenous variations in tax policy decisions via their reading of narrative records. The second one is a version of the fiscal spending shocks proposed by Auerbach and Gorodnichenko (2012), which we obtain by estimating an expectations-augmented fiscal VAR in which news spending

\footnotetext{
${ }^{3}$ Section 3 provides an illustrative example on how our methodology works when one instrument is used to simultaneously proxy two shocks.
} 
shocks à la Ramey (2011) are allowed to exert a contemporaneous impact on fiscal spending. ${ }^{4}$ To our knowledge, ours is the first exercise in which a proxy for unexpected fiscal spending shocks is used to estimate the US fiscal spending multiplier in a proxySVAR context. In this sense, our contribution complements the one by Ramey (2011), who focuses on the output response to anticipated fiscal spending shocks. ${ }^{5}$ The third instrument we use in our analysis is the factor utilization-adjusted total factor productivity series produced by Fernald (2014), which - following Caldara and Kamps (2017) we exploit to identify shocks to the business cycle. Finally, in an extended version of the model that also features inflation, we use a fourth instrument, i.e., the oil shocks series proposed by Hamilton (2003) to instrument inflation shocks. While we use the first two proxies to directly identify the fiscal shocks of interest, the latter two instruments carry information for the identification of non-fiscal shocks that, via the moments related to the covariance matrix of the fiscal SVAR, can be exploited to identify fiscal elasticities and, consequently, spending and tax multipliers. Importantly, the assessment of the statistical uncertainty surrounding our point estimates is undertaken by computing confidence bands via the Moving Block Bootstrap (MBB) resampling scheme proposed by Jentsch and Lunsford (2019a), which suitably takes into account the distributional properties of the VAR innovations and of the proxies used in our analysis. ${ }^{6}$

Findings. Our point estimates of the fiscal spending multiplier fall in the 1.6-2.1 range. These point estimates, which are supported by different sets of instruments and model specifications, are statistically in line with the one by Caldara and Kamps' (2017), who work with non-fiscal instruments only, Canova and Pappa (2007), who work with sign restrictions in a panel SVAR framework modeling US and EU data, and Leeper, Traum, and Walker (2017), who work with different micro-founded structural frameworks. Our estimates also support the 1.6 figure used by Christina Romer - at

\footnotetext{
${ }^{4}$ The idea is to purge the one-step ahead fiscal spending forecast error by the component which can actually be anticipated on the basis of narrative records. Auerbach and Gorodnichenko (2012) is the first paper conducting a VAR exercise with this measure. They use real-time professional forecasts, available since 1966, to control for expectations not already absorbed by their VAR. Our choice of using Ramey's (2011) news spending shock as a control is due to its availability, which covers the entire sample we work with (1950Q1-2006Q4).

${ }^{5}$ Ramey and Zubairy (2018) estimate the multiplier generated by anticipated fiscal spending shocks with a local projections approach. See Plagborg-Møller and Wolf (2018) on the mapping between local projections and proxy-SVARs.

${ }^{6}$ The MBB correctly reconstructs the variability of estimated impulse response functions in situations featuring conditional heteroskedasticity in VAR innovations and/or zero-censored proxy as Mertens and Ravn's. Section 3 elaborates on this point. For a discussion on this resampling scheme vs. alternatives, see Brüggemann, Jentsch, and Trenkler (2016), Jentsch and Lunsford (2019b) and Mertens and Ravn (2019).
} 
the time Chair of President Obama's Council of Economic Advisers - to predict the job gains possibly generated by the stimulus package approved by the US Congress in February 2009. ${ }^{7}$

Turning to the tax multiplier, depending on the model specification and the instruments we rely upon, we can support point estimates ranging from 0.7 to 3.6. First, we show that our proxy-SVAR framework exactly replicates the "high" tax multiplier by Romer and Romer's (2010) and Mertens and Ravn's (2011b, 2012, 2013, 2014) and the "low" tax multiplier estimated by Caldara and Kamps (2017) when using their instruments in isolation (respectively, a narrative measure of tax shocks and a measure of TFP). Crucially, the latter estimate - the 0.7 value of the peak realization of the tax multiplier - is obtained under the assumption that the TFP proxy is orthogonal to the tax shock. However, economic intuition suggests that shocks driving the business cycle might also be behind fluctuations in tax revenues. ${ }^{8}$ In our context, this implies that the TFP proxy could be also correlated with tax shocks, other than output shocks. One of the advantages of our approach is that we can relax the TFP-tax shocks orthogonality condition if other (testable) restrictions are met, so that we can use the TFP proxy to simultaneously instrument output and tax shocks. When we do so, we find a striking result, i.e., our estimate of the tax multiplier moves from 0.7 to 3.6. Interestingly, this estimate is in line with the 3.7 multiplier found by Mertens and Ravn (2011a), who estimate the response of the US tax revenues to a technology shock identified with long-run restrictions.

Role of the TFP-tax shocks orthogonality condition. Why does relaxing the orthogonality condition drive the multiplier upward? The rationale for this result is the impact of the correlation between TFP and tax shocks on the estimate of the output-tax revenues elasticity. Our model points to a tax elasticity around 3.8. When imposing orthogonality between TFP and tax shocks, the estimate of the output-tax elasticity drops to 2.1. This latter figure is basically the same as the one employed by Blanchard and Perotti (2002) and provided by the OECD (Giorno, Richardson, Roseveare, and van den Noord (1995)), which is 2.08. However, as pointed out by

\footnotetext{
${ }^{7}$ See https://voxeu.org/article/determining-size-fiscal-multiplier. Auerbach and Gorodnichenko (2012), Bachmann and Sims (2012), Caggiano, Castelnuovo, Colombo, and Nodari (2015), and Ghassibe and Zanetti (2019) find this multiplier to be larger in recessions. For contrasting evidence, see Ramey and Zubairy (2018). Evidence on state-dependent output effects of tax shocks is provided by Sims and Wolff (2018).

${ }^{8}$ Mountford and Uhlig (2009) identify "business cycle" shocks by assuming them to generate a positive conditional correlation between output and tax revenues. They point out that this assumption is consistent with a number of theoretical views.
} 
Mertens and Ravn (2014), such estimate is likely to be affected by endogeneity issues related to the estimation of the tax base-tax revenues and the output-tax base elasticities across different categories of tax revenues. Our exercises support Mertens and Ravn's (2014) reasoning. Also, our results confirm the link between output-tax elasticities and tax multiplier already unveiled by Mertens and Ravn (2014) (via counterfactual simulations) and Caldara and Kamps (2017) (via analytical derivations).

Robustness to the use of multiple instruments. A natural question at this point is: Are our findings robust to the joint use of multiple instruments? We address this question by estimating an extended version of our proxy-SVAR that also includes inflation and a policy rate. We identify shocks by using all four proxies contemporaneously, i.e., the Auerbach and Gorodnichenko (2012) proxy for the fiscal spending shock, the Mertens and Ravn (2012) proxy for the tax shock, the TFP proxy for the output shock and, depending on the specification, the tax shock, and the Hamilton (2003) oil shocks proxy for the inflation shock. Even when multiple instruments are at play, our findings are: i) the crucial role played by the TFP-tax shocks orthogonality condition is confirmed when using multiple instruments; ii) when relaxing the TFP-tax shocks orthogonality assumption, a larger tax elasticity and a tax multiplier larger than three arise.

While the modeling of the TFP-tax shocks correlation is crucial to unveil a large tax multiplier, such correlation does not seem to play any significant role when it comes to quantifying the spending multiplier. Such multiplier is actually pretty robust across different sets of proxies. Why? The intuition goes back to the central role played by fiscal elasticities. While the output-tax elasticity is sensitive to assumptions about the moment conditions relating instruments and VAR innovations, the output-spending elasticity is not. The reason is that the latter is close to zero in the data, a result in line with the institutional characteristics of the US system (Blanchard and Perotti (2002)). Hence, the endogeneity issue, if present, is much less severe for the estimation of the output-spending elasticity and, therefore, the spending multiplier.

This paper is structured as follows. Section 2 discusses how our paper relates to the extant literature. Section 3 presents the methodology, the data, and the way in which we compute the multipliers. Section 4 documents our results. Section 5 documents some robustness checks. Section 6 concludes. 


\section{Relation to the literature}

Our work is related to the fiscal proxy-SVAR literature that has used fiscal and nonfiscal instruments to quantify the size of the spending and the tax multiplier. The use of TFP shocks as an instrument to compute fiscal multipliers is inspired by Caldara and Kamps (2017). Their analysis of the fiscal multipliers features two parts. First, they show that the heterogeneity of estimates of the fiscal multipliers in the literature can be explained by the different fiscal elasticities implied by the different methodologies at work (zero restrictions, sign restrictions, proxy-SVARs). Then, they use non-fiscal instruments to estimate fiscal elasticities and work out the fiscal multipliers by exploiting the information coming from the covariance matrix of the VAR residuals. They find the fiscal spending multiplier to be larger than one and bigger than the tax multiplier. We reach a similar conclusion on the fiscal spending multiplier, but a strikingly different one on the tax multiplier. As explained above, this difference is due to the different assumption on the TFP instrument-tax shocks relationship, i.e., the imposition of orthogonality by Caldara and Kamps (2017) that we do not entertain. Several other elements separate our investigation from theirs. First, we jointly employ fiscal and nonfiscal instruments to estimate the multipliers. Doing so enables us to show that, while the estimate of the fiscal spending multiplier is robust across different sets of proxies, that of the tax multiplier is not. A second, related point is that, for the estimation of the latter multiplier, we unveil that relaxing the orthogonality (exogeneity) of the TFP instrument to tax shocks is crucial for correctly estimating the output effects of tax cuts. Third, our methodology enables us to formally assess the validity of the instruments we use without appealing to information external to that of the original VAR and of the external instruments already used to identify the targeted shocks. Differently, Caldara and Kamps (2017) need to appeal to fiscal instruments to test the exogeneity (orthogonality) of the non-fiscal instruments they use as proxies in their approach. Fourth, our AC-SVAR representation of proxy-SVARs enables us to work with overidentified models and formally test some of the restrictions imposed by the literature, e.g., the zero output-spending elasticity imposed by Blanchard and Perotti (2002) and Auerbach and Gorodnichenko (2012). Fifth, we cover the case of the estimation of the fiscal spending multiplier related to an unexpected fiscal spending shock, which they do not study.

Our analysis is related to recent contributions by Karel Mertens and Morten Ravn. We share with Mertens and Ravn (2013) the idea of using narratives on exogenous variations in tax revenues to directly identify US tax shocks. However, our method 
allows us to jointly instrument fiscal and non-fiscal shocks, with the advantage of not being committed to Cholesky-type constraints when multiple instruments are used to identify multiple shocks. Because of this flexibility, we can account for cases where one proxy may instrument more than one structural shock, a crucial fact behind our empirical results. We share with Mertens and Ravn (2014) the idea that the proxySVAR approach is not necessarily confined to a "partial identification" approach. This means that if the proxies are properly combined with a few additional restrictions that characterize the on-impact coefficients associated with the non-instrumented shocks, one can identify all structural shocks of the system, not just the instrumented ones. Mertens and Ravn (2014) exploit this strategy in Section 3 of their article (p. 60), where to identify all shocks of their SVAR they complement the restrictions provided by the proxy used to identify the tax shock with one additional restriction, represented by the noninstantaneous reaction of government spending to changes in economic activity. Doing so, they not only identify the tax shock but also track the dynamic causal effects of fiscal spending shocks on output. However, while Mertens and Ravn (2014) instrument the tax shock only, our AC-SVAR model features specifications in which both the tax and fiscal spending shocks (as well as non-fiscal shocks) are instrumented jointly. Moreover, while the estimation in both Mertens and Ravn (2013) and Mertens and Ravn (2014) is based on instrumental variable methods, we rely on maximum likelihood, which is one of the benefits of representing the proxy-SVAR in the AC-SVAR form. This is important, as we can use likelihood ratio tests as the "metric" for the empirical evaluation of the estimated proxy-SVARs in presence of overidentification restrictions.

The focus of this paper is on the output effects of unexpected variations in fiscal spending and taxes. Classic papers in this area are Blanchard and Perotti (2002), who rely on zero restrictions and institutional information about the US tax and transfer system to identify fiscal shocks. They find a fiscal spending multiplier larger or smaller than the tax multiplier depending on details of the VAR specification. Differently, Mountford and Uhlig (2009) work with sign restrictions and find a large tax multiplier and a spending multiplier lower than one. Our paper complements the analysis on the fiscal multipliers due to changes in announced future fiscal policies (see, among others, Fisher and Peters (2010), Ramey (2011), Leeper, Walker, and Yang (2013), Ricco (2016), Forni and Gambetti (2016), Ben Zeev and Pappa (2017)). It also complements the recent investigations on the output effects of debt consolidation plans, which are surveyed in Alesina, Favero, and Giavazzi (2018, 2019). In line with most of the literature, this paper deals with the output effects of shocks to federal tax revenues. 
Papers dealing with narrower definitions of tax shocks are Barro and Redlick (2011) and Mertens and Ravn (2013). Our focus is on the effects of fiscal shocks on aggregate output. Papers dealing with the distributional effects of fiscal shocks are Mertens and Montiel Olea (2018) and Zidar (2019).

Our analysis unveils the source of the heterogeneneity in the empirical estimates of tax multipliers. A related contribution is Chahrour, Schmitt-Grohe, and Uribe (2012), who show that the different tax multipliers obtained by Blanchard and Perotti (2002) - close to 1 - and Romer and Romer (2010) - around 3 - are not due to the different reduced-form representations of their econometric models (a VAR in the former case vs. a local projection equation in the latter). They point to the different identification assumptions behind the two approaches as the source of the different estimates of the tax multiplier. Within the proxy-SVAR class, our paper sheds light on the role played by different identification schemes in delivering substantially different estimates of the tax multiplier. Moreover, it shows that such different identification schemes are significantly more problematic for the estimation of the tax multiplier than for that of the fiscal spending multiplier.

\section{Methodology, data and multipliers}

AC-SVAR: Identification. Consider the following reduced-form VAR system

$$
\Pi(L) Y_{t}=u_{t}
$$

where $Y_{t}$ is a vector of $n$ observables, $\Pi(L) \equiv I_{n}-\Pi_{1} L-\Pi_{2} L^{2}-\ldots-\Pi_{p} L^{p}$ is the matrix polynomial collecting the coefficients associated with the $p$ lags of the variables $\left(Y_{t-p}=L^{p} Y_{t}\right)$, and $u_{t}$ is the vector of innovations with covariance matrix $E\left(u_{t} u_{t}^{\prime}\right)=\Sigma_{u} \cdot{ }^{9}$

Let the mapping between the vector of innovations $u_{t}$ and that of structural shocks $\varepsilon_{t}$ be

$$
u_{t}=B \varepsilon_{t}
$$

where it is assumed that $E\left(\varepsilon_{t} \varepsilon_{t}^{\prime}\right)=I_{n}$. We focus on the identification of a subset of $k \leq n$ structural shocks $\varepsilon_{1, t}$, where $\varepsilon_{t}=\left(\varepsilon_{1, t}^{\prime}, \varepsilon_{2, t}^{\prime}\right)^{\prime} . \varepsilon_{1, t}$ collects the $k$ shocks of primary interest of the analysis, which in our framework are the fiscal shocks (spending shock and tax shock), but possibly also non-fiscal shocks. $\varepsilon_{2, t}$ collects the remaining $n-k$

\footnotetext{
${ }^{9}$ Constants and other deterministic terms are omitted for brevity. The extension of our formal expressions to cases in which constants and deterministic trends are present is straightforward.
} 
non-fiscal structural shocks of the system. ${ }^{10}$ Then, without loss of generality, we can re-write the mapping (2) in the form

$$
u_{t}=B_{1} \varepsilon_{1, t}+B_{2} \varepsilon_{2, t}
$$

where $B=\left(B_{1}, B_{2}\right), B_{1}$ contains the instantaneous impact coefficients associated with the shocks in $\varepsilon_{1, t}$, and $B_{2}$ pertains to the instantaneous impact coefficients associated with the shocks in $\varepsilon_{2, t}$. We have ordered the shocks $\varepsilon_{1, t}$ first for convenience: as it will be clear below, the ordering of the variables is irrelevant in our framework.

Assume that a vector of $k$ instruments $v_{z, t}$ for the shock $\varepsilon_{1, t}$ is available. For such instruments to be valid, the following two conditions have to hold:

$$
\begin{aligned}
& E\left(v_{z, t} \varepsilon_{1, t}^{\prime}\right)=\Phi, \quad \operatorname{rank}(\Phi)=k \\
& E\left(v_{z, t} \varepsilon_{2, t}^{\prime}\right)=0_{k \times(n-k)} .
\end{aligned}
$$

Condition (4) states that the $k$ instruments have to be relevant, i.e., significantly correlated with the $k$ structural shocks of interest. $\Phi$ is a $k \times k$ full column rank matrix containing "relevance" parameters, and the rank condition in (4) implies that each column of $\Phi$ is non-zero and carries important information on the shocks in $\varepsilon_{1, t}$. Condition (5) states that in the absence of further restrictions, the instruments have to be orthogonal to the non-instrumented shocks. The conditions (4)-(5) can be conveniently summarized for our purposes via the expression

$$
v_{z, t}=\Phi \varepsilon_{1, t}+\omega_{t}
$$

which establishes that the instruments are connected to the instrumented structural shocks via the matrix $\Phi$, up to the measurement error term $\omega_{t}$. The measurement error is assumed to be independent on $\varepsilon_{t}=\left(\varepsilon_{1, t}^{\prime}, \varepsilon_{2, t}^{\prime}\right)^{\prime}$ and has covariance matrix $\Sigma_{\omega}$.

Angelini and Fanelli (2019) propose a novel approach to the identification and estimation of proxy-SVARs. They work with an augmented system that jointly accounts for the observables $Y_{t}$ and the instruments $v_{z, t} \equiv Z_{t}-E\left(Z_{t} \mid \mathcal{F}_{t-1}\right)$, where $Z_{t}$ collect the "raw" variables the instruments are constructed upon, and $\mathcal{F}_{t-1}$ is the econometrician's

\footnotetext{
${ }^{10}$ In our framework, the number of instrumented shocks $k$ can be equal to the number of variables of the VAR $n$. Our framework covers the case $\varepsilon_{1, t} \equiv \varepsilon_{t}$, meaning that we can potentially instrument all structural shocks of the system. This is a novelty in the proxy-SVAR literature, which will be fully explored in our empirical exercises presented below. See also the example in the text.
} 
information set at time $t-1$. They denote the resulting model with the acronym ACSVAR, where "A" stands for "augmented" and "C" for "constrained" because of the (zero) constraints the model features. The AC-SVAR model reads as follows: ${ }^{11}$

$$
\left(\begin{array}{cc}
\Pi(L) & 0_{n \times k} \\
\Gamma(L) & \Theta(L)
\end{array}\right)\left(\begin{array}{c}
Y_{t} \\
Z_{t}
\end{array}\right)=\left(\begin{array}{c}
u_{t} \\
v_{z, t}
\end{array}\right)
$$

where $\Gamma(L)$ and $\Theta(L)$ are matrix polynomials as $\Pi(L)$ in the VAR (1), with $\Gamma(L) \equiv$ $\Gamma_{1} L+\Gamma_{2} L^{2}+\ldots+\Gamma_{s} L^{s}$ and $\Theta(L) \equiv I_{k}-\Theta_{1} L-\Theta_{2} L^{2}-\ldots-\Theta_{q} L^{q}$. The AC-SVAR model allows the variables $Z_{t}$ to be persistent (via $\Theta(L)$ ), and possibly the lags of $Y_{t}$ to be predictors of $Z_{t}$ (via $\Gamma(L)$ ). Obviously, $\Gamma(L)=0_{k \times n}$ and $\Theta(L)=I_{k}$ when $v_{z, t} \equiv Z_{t}$, i.e., when the external instruments are already expressed in innovation form and need not be filtered out on past information. ${ }^{12}$

In the AC-SVAR model, the relationships between innovations, instruments and shocks is obtained by coupling (3) with (6). The resulting system is the following:

$$
\left(\begin{array}{c}
u_{t} \\
v_{z, t}
\end{array}\right)=\left(\begin{array}{ccc}
B_{1} & B_{2} & 0_{n \times k} \\
\Phi & 0_{k \times(n-k)} & \Sigma_{\omega}^{1 / 2}
\end{array}\right)\left(\begin{array}{c}
\varepsilon_{1, t} \\
\varepsilon_{2, t} \\
\omega_{t}^{o}
\end{array}\right)
$$

where $\omega_{t}^{o}$ denotes the measurement error term $\omega_{t}$ in (6) normalized to have unit variance. $^{13}$

System (7)-(8) can be written in compact form. Consider the following definitions:

$$
W_{t} \equiv\left(\begin{array}{c}
Y_{t} \\
Z_{t}
\end{array}\right), \eta_{t} \equiv\left(\begin{array}{c}
u_{t} \\
v_{z, t}
\end{array}\right), \quad \widetilde{\Psi}(L) \equiv\left(\begin{array}{cc}
\Pi(L) & 0_{n \times k} \\
\Gamma(L) & \Theta(L)
\end{array}\right), \quad \widetilde{G} \equiv\left(\begin{array}{ccc}
B_{1} & B_{2} & 0_{n \times k} \\
\Phi & 0_{k \times(n-k)} & \Sigma_{\omega}^{1 / 2}
\end{array}\right)
$$

where $W_{t}$ and $\eta_{t}$ are $(n+k)$-dimensional, and " " indicates that $\widetilde{\Psi}(L)$ and $\widetilde{G}$ incorporate

\footnotetext{
${ }^{11}$ A detailed exposition of the properties of the AC-SVAR approach can be found in Angelini and Fanelli (2019). We use their notation to facilitate the mapping between their derivations and our presentation of their framework and its properties.

${ }^{12}$ Given the large number of coefficients featured by the system of equations (7), in the empirical analyses presented below we impose that $\Theta(L)$ is diagonal when $k>1$, i.e., the instruments are assumed to be dynamically unrelated to each other. These restrictions are supported by the data, i.e., the (cross-)correlations among the instruments used throughout the analysis are statistically equal to zero. Furthermore, in all estimated models discussed below the lag order $q$ of $\Theta(L)$ and $s$ of $\Gamma(L)$ is set to four, in line with the VAR lag order $p$.

${ }^{13}$ Formally, $\Sigma_{\omega}^{1 / 2}$ in (8) is a symmetric positive definite matrix such that the variance of the measurement error $\omega_{t}=\Sigma_{\omega}^{1 / 2} \omega_{t}^{o}$ is equal to $\Sigma_{\omega}$. In our setup $\Sigma_{\omega}^{1 / 2}$ could also correspond to the Cholesky factor of $\Sigma_{\omega}$, see Angelini and Fanelli (2019) for details.
} 
by construction a set of zero restrictions. Then, system (7)-(8) can be expressed as:

$$
\begin{aligned}
\widetilde{\Psi}(L) W_{t} & =\eta_{t} \\
\eta_{t} & =\widetilde{G} \xi_{t}
\end{aligned}
$$

where $E\left(\eta_{t} \eta_{t}^{\prime}\right)=\Sigma_{\eta}=\left(\begin{array}{cc}\Sigma_{u} & \Sigma_{u, v_{z}}^{\prime} \\ \Sigma_{u, v_{z}} & \Sigma_{\omega}\end{array}\right)$, and $E\left(\xi_{t} \xi_{t}^{\prime}\right)=I_{n+k}$.

Equations (9)-(10) represent the proxy-SVAR as a "larger" SVAR system. Formally it reads as a structural "B-model" (Lütkepohl (2005)) characterized by a certain number of zero restrictions in the autoregressive coefficients $\widetilde{\Psi}(L)$, and in the matrix of "structural parameters" $\widetilde{G} \cdot{ }^{14}$ From eq. (10), the covariance restrictions are given by

$$
\Sigma_{\eta}=\widetilde{G} \widetilde{G}^{\prime}
$$

and it is easily seen that these generate, among others, the "core" covariance restrictions of proxy-SVAR analysis $\Sigma_{v_{z}, u}=\Phi B_{1}^{\prime}$ (see, among others, Stock and Watson (2012), Mertens and Ravn (2013), Stock and Watson (2018), and Angelini and Fanelli (2019)).

The matrix $\widetilde{G}$ in (10) fully incorporates the restrictions implied by the $k$ instruments used for $\varepsilon_{1, t}$. The relevance condition (4) is captured by the non-zero coefficients that enter the matrix $\Phi$ in the $(2,1)$ block of $\widetilde{G}$; the orthogonality (exogeneity) conditions (5) correspond to the block of $k(n-k)$ zeros in the position $(2,2)$ of $\widetilde{G}$. However, the relevance and orthogonality conditions are not sufficient alone to recover all structural shocks in $\varepsilon_{t}=\left(\varepsilon_{1, t}^{\prime}, \varepsilon_{2, t}^{\prime}\right)^{\prime}$. Angelini and Fanelli (2019) derive the necessary and sufficient rank conditions and the necessary order conditions for this to happen, and show that it is necessary to impose some "additional" constraints on the coefficients of $B_{1}, \Phi$ and $B_{2}$ that form the matrix $\widetilde{G}$ in (8). (See also the Supplementary Appendix in Olea, Stock, and Watson (2020).)

Two remarks are in order. First, our analysis covers the case $r=n$, namely we can potentially instrument all the structural shocks of the fiscal SVAR, a novelty in the proxy-SVAR literature which we will employ in Section 4.4. Second, while for $k>1$ the matrix of relevance parameters $\Phi$ must be nonsingular, it needs not be diagonal, meaning that a single instrument in $v_{z, t}$, say $v_{z, i, t}$, may instrument not only the structural shocks $\varepsilon_{1, i, t}$ but, potentially, also other shocks in $\varepsilon_{1, t} \cdot{ }^{15}$ More important,

\footnotetext{
${ }^{14}$ See Arias, Rubio-Ramírez, and Waggoner (2018) for a similar specification based on the "A-model" and a Bayesian approach.

${ }^{15}$ Similarly, Mertens and Ravn (2013) consider narrative accounts of shocks to average personal income (PI) and corporate income (CI) tax rates for the US to identify two tax shocks $(k=2)$, and observe that (p. 1223) "it appears inappropriate to treat the narrative PI (CI) tax changes as
} 
under certain restrictions on the coefficients of $B_{1}, \Phi$ and $B_{2}$ that form the matrix $\widetilde{G}$ in (8), our analysis features cases where some proxies may violate the orthogonality condition. In other words, proxies used to instrument the shocks in $\varepsilon_{1, t}$ may potentially instrument also some of the shocks in $\varepsilon_{2, t}$, a scenario which is best understood by the simple example discussed next.

If the SVAR model (9)-(10) is identified, the matrix $\widetilde{G}$ (as well as the non-zero parameters in $\widetilde{\Psi}(L)$ ) can be estimated via maximum likelihood. ${ }^{16}$ When the restrictions on $\widetilde{G}$ are overidentifying, likelihood ratio tests for the overidentification restrictions provide an empirical assessment of the estimated proxy-SVAR.

AC-SVAR: One proxy for two structural shocks. To shed light on our approach, we discuss a specific example where one proxy is used to instrument two shocks. We build our argument in two steps, starting with the standard case of one instrument for one shock before moving to the one proxy - two shocks case. Anticipating what we will do in Sections 4.2 and 4.3, suppose we use a measure of TFP as instrument for the output shock. Then, the counterpart of (3) in our baseline model reads as follows:

$$
\left(\begin{array}{c}
u_{t}^{t r} \\
u_{t}^{g} \\
u_{t}^{y}
\end{array}\right)=\left(\begin{array}{cc}
b_{t r, t r} & b_{t r, g} \\
b_{g, t r} & b_{g, g} \\
b_{y, t r} & b_{y, g}
\end{array}\right)\left(\begin{array}{c}
\varepsilon_{t}^{t r} \\
\varepsilon_{t}^{g}
\end{array}\right)+\left(\begin{array}{c}
b_{t r, y} \\
b_{g, y} \\
b_{y, y} \\
B_{1}
\end{array}\right) \varepsilon_{t}^{y},
$$

where $u_{t}=\left(u_{t}^{t r}, u_{t}^{g}, u_{t}^{y}\right)^{\prime}$ is the vector of the VAR innovations, $u_{t}^{t r}$ is the disturbance associated with the equation for tax revenues, $u_{t}^{g}$ is the disturbance associated with the equation for fiscal spending, $u_{t}^{y}$ is the disturbance associated with the equation for output, $\varepsilon_{t}^{t r}$ and $\varepsilon_{t}^{g}$ denote the tax and the fiscal spending shock (respectively), and $\varepsilon_{t}^{y}$ is the output shock, which in this example is directly instrumented $(k=1)$ by the TFP proxy. Such proxy is denoted $v_{t}^{T F P}$, and the counterpart of (6) is given by the equation

$$
v_{t}^{T F P}=\phi_{1} \varepsilon_{t}^{y}+\omega_{t}^{T F P}
$$

where $\phi_{1}=\operatorname{Cov}\left(v_{t}^{T F P}, \varepsilon_{t}^{y}\right)$ is the relevance parameter which captures the connection between the TFP proxy and the output shock, and $\omega_{t}^{T F P}$ is the associated measurement

uncorrelated with exogenous shocks to the corporate (personal) tax rate". Thus, Mertens and Ravn (2013) estimate a "full" matrix $\Phi$ (not a diagonal one) and impose the additional restrictions necessary to identify the two shocks other the two proxies elsewhere in their proxy-SVAR.

${ }^{16}$ When the restrictions that characterize $\widetilde{G}$ are zero constraints, separable across columns, a convenient way to study the identification of the proxy-SVAR is to check whether the sufficient conditions for global identification in Theorem 2 of Rubio-Ramírez, Waggoner, and Zha (2010) are met. See Angelini and Fanelli (2019) for some examples. 
error with standard deviation $\sigma_{\omega, T F P}$. As is known from standard proxy-SVAR analysis, the TFP proxy alone would suffice to identify the output shock under the condition $\phi_{1} \neq$ 0 . However, to estimate the fiscal multipliers, we need to achieve "full identification", i.e., we also have to identify the non-instrumented fiscal shocks in $\varepsilon_{2, t} \equiv\left(\varepsilon_{t}^{t r}, \varepsilon_{t}^{g}\right)^{\prime}$. To do so, we need at least one additional restriction other than the proxy, and in this example identification is achieved by properly restricting the coefficients $b_{*, *}$ in the block $B_{2}$ in (12). We consider two constraints. First, $b_{t r, g}=0$, which maintains that tax revenues do not instantaneously respond (within the quarter) to the fiscal spending shock. By imposing $b_{t r, g}=0$, we obtain a just identified model. Second, following Blanchard and Perotti (2002) and Mertens and Ravn (2014), we posit that fiscal spending does not react contemporaneously (within the quarter) to changes in economic activity captured by the output shock, i.e. $b_{g, y}=0$ in the block $B_{1}$ in (12). Overall, the TFP proxy and the conditions $b_{t r, g}=0$ and $b_{g, y}=0$ imply the following structure for the matrix $\widetilde{G}$ in (8):

$$
\widetilde{G}=\left(\begin{array}{cccc}
b_{t r, t r} & 0 & b_{t r, y} & 0 \\
b_{g, t r} & b_{g, g} & 0 & 0 \\
b_{y, t r} & b_{y, g} & b_{y, y} & 0 \\
0 & 0 & \phi_{1} & \sigma_{\omega, T F P}
\end{array}\right)
$$

It can be shown that the AC-SVAR model in (14) is overidentified, which implies that it is testable. ${ }^{17}$

We next move to the case of interest, where one proxy is used to instrument for two shocks. Economic intuition suggests that tax revenues are cyclical, hence TFP shocks may be behind their volatility as well. In this case, the equation for the TFP proxy becomes

$$
v_{t}^{T F P}=\phi_{1} \varepsilon_{t}^{y}+\phi_{2} \varepsilon_{t}^{t r}+\omega_{t}^{T F P}
$$

where $\phi_{1}$ has the same interpretation as before, while $\phi_{2}=\operatorname{Cov}\left(v_{t}^{T F P}, \varepsilon_{t}^{t r}\right)$ is the relevance parameter which captures the relationship between the TFP proxy and the tax shock. Equation (15) relaxes the orthogonality of the TFP proxy to the tax shock and keeps the orthogonality to the fiscal spending shock unchanged. Is the model identified? Now, the counterpart of the matrix $\widetilde{G}$ in (8) is:

$$
\widetilde{G}=\left(\begin{array}{cccc}
b_{t r, t r} & 0 & b_{t r, y} & 0 \\
b_{g, t r} & b_{g, g} & 0 & 0 \\
b_{y, t r} & b_{y, g} & b_{y, y} & 0 \\
\phi_{2} & 0 & \phi_{1} & \sigma_{\omega, T F P}
\end{array}\right)
$$

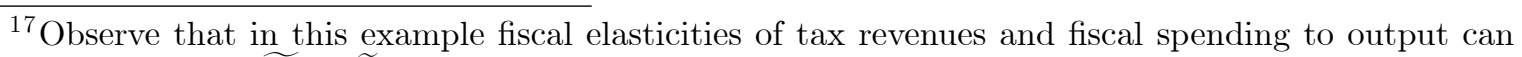
be recovered from $\widetilde{G I} \equiv \widetilde{G}^{-1}$, see Section 4 .
} 
which is the same as in (14), the only difference being the non-zero parameter $\phi_{2}$ in the first column. As before, it is possible to show that the AC-SVAR model is just identified. This proxy-SVAR nests the previous one, which holds under the orthogonality condition $\phi_{2}=0$. Hence, $\phi_{2}$ can be estimated, along with the uncertainty surrounding its point estimate. A confidence interval around $\phi_{2}$ can be interpreted as prima facie evidence on the relationship between the TFP proxy and tax shocks. Notice that hypotheses of the type $\phi_{2}=\breve{\phi}_{2}$, where $\breve{\phi}_{2}$ are guess values for the relevance parameter, are over-identifying and hence testable against the data.

Data and instruments. Our baseline model includes the following endogenous variables: gross domestic product, $y_{t}$, real per-capita federal tax revenue, $t r_{t}$, and government spending, $g_{t}$. The last series is defined as the sum of government consumption and investment. Following Caldara and Kamps (2017), these series are expressed in logs and per capita terms and are detrended by removing a linear trend via OLS regressions. ${ }^{18}$ Thus, $Y_{t}=\left(y_{t}, t r_{t}, g_{t}\right)^{\prime}$ is the vector of endogenous variables in our baseline specifications. We also consider specifications that also include consumer price inflation $\pi_{t}$ and the 3 -month (nominal) Treasury bill rate $i_{t}$, hence $Y_{t}=\left(y_{t}, t r_{t}, g_{t}, \pi_{t}, i_{t}\right)^{\prime}$ is the vector of endogenous variables of our "extended" model.

As anticipated in the Introduction, we include up to four proxies (considering the extended model) in the vector $Z_{t}$ to achieve identification, two fiscal instruments and two non-fiscal ones. The two fiscal instruments are Mertens and Ravn's (2011) series of unanticipated tax shocks (denoted $M R$ ), which is a subset of and Romer and Romer's (2010) shocks identified by studying narrative records on tax policy decisions, and a novel series of unanticipated fiscal spending shocks inspired by Auerbach and Gorodnichenko's (2012) contribution (denoted $A G$ ). This latter proxy is the residual of the OLS regression of the log of fiscal spending over a linear trend, the spending news shocks series proposed by Ramey (2011), and three lags of output, fiscal spending, tax revenues (all in logs), and Ramey's series. The idea of controlling for the contemporaneous (as well as the past) realizations of Ramey's (2011) anticipated shocks is that of focusing on the truly unanticipated component of fiscal spending, which is our object of interest here. As stressed by Mertens and Ravn (2014), using instruments that confound unanticipated and news shocks may lead to a failure of the exogeneity assumption, and therefore invalidate the econometric analysis.

Turning to non-fiscal instruments, the instrument employed for the output shock is

\footnotetext{
${ }^{18}$ All the results of the paper are robust to re-estimating the VAR with variables in log-levels and including a linear trend. Results are shown in the Appendix.
} 
the total factor productivity series by Fernald (2014), denoted TFP, which is adjusted for changes in factor utilization. Finally, when working with an "extended" version of our framework which also includes inflation and a policy rate, we use the oil shocks series by Hamilton (2003), denoted $O I L$, which is a nonlinear function of the changes in the nominal price of crude oil. ${ }^{19}$

Estimation and bootstrap inference. We estimate our model with quarterly US data, sample: 1950Q1-2006Q4. This sample choice facilitates the comparison of our results with those documented in the literature (see e.g. Caldara and Kamps (2017), Mertens and Ravn (2014)). Moreover, it avoids us the need of facing the challenging estimation of the fiscal multipliers in presence of the zero lower bound (for contributions on this issue, see Christiano, Eichenbaum, and Rebelo (2011) and Wieland (2018)). The SVAR for $Y_{t}$ includes $p=4$ lags of the endogenous variables and a constant. The corresponding AC-SVAR specification is obtained by appending the external instrument(s) $Z_{t}$ to $Y_{t}$, forming a SVAR system for $W_{t}$ modeled as in (9)-(10). As already observed, instruments alone do not generally carry enough information to identify all the elements of the matrix $\widetilde{G}$ in (8) that are needed to compute the fiscal multipliers. In such cases, restrictions on the matrices $B_{1}, \Phi$ and $B_{2}$ will be employed to achieve (full) identification. These additional restrictions are discussed case-by-case in the next section. The model is estimated by maximum likelihood.

Bootstrap inference on the impulse response functions computed from proxy-SVARs has recently been debated by Mertens and Montiel Olea (2018), Jentsch and Lunsford (2019b), Mertens and Ravn (2019), Jentsch and Lunsford (2019a), and Olea, Stock, and Watson (2020). Elaborating on results by Brüggemann, Jentsch, and Trenkler (2016), Jentsch and Lunsford (2019a) show that asymptotic inference in these models is still "standard" (i.e., based on the Gaussian distribution, albeit the expressions for the asymptotic covariance matrices of the estimators may be rather complex) under fairly general conditions on the VAR innovations $u_{t}$ and the instruments $v_{z, t}$. These include two main situations that are relevant for our estimates. One is the occurrence of conditionally heteroskedastic (e.g. ARCH-type) VAR innovations, a feature that we find in the data. The other is the case in which the dynamics of the external instruments

\footnotetext{
${ }^{19}$ All series but the instrument inspired by the Auerbach and Gorodnichenko (2012) paper are available in the replication package of the Caldara and Kamps (2017) paper, which is available at Dario Caldara's webpage: https://sites.google.com/view/dariocaldara/publications . Our AG instrument is available upon request.
} 
is not as in (6) but is approximated by the zero-censored model:

$$
v_{z, t}=D_{t}\left(\Phi \varepsilon_{1, t}+\omega_{t}\right)
$$

where $D_{t}$ is a $k \times k$ diagonal matrix with dummy variables on the diagonal that play the role of zero censoring the proxy. In particular, let $D_{i, t}$ be the dummy associated with the proxy $v_{z, i, t}, i=1, . . k$, then $D_{i, t}$ takes value 1 with probability $p_{i}$ and value 0 with probability $1-p_{i}$, implying that $v_{z, i, t}$ can be either zero (with probability $1-p_{i}$ ) or can take both positive and negative values (with probability $p_{i}$ ). In the empirical analyses discussed in the next section, Mertens and Ravn's (2011) series of unanticipated tax shocks, $M R_{t}$, is characterized by a type of dynamics consistent with (17). Jentsch and Lunsford (2019b) show that in these situations, the MBB method is the resampling scheme which correctly reconstructs the variability of estimated impulse response functions (see also Jentsch and Lunsford (2019a)).

Based on these observations, we apply the MBB resampling scheme to build confidence bands for estimated parameters of interest and the estimated fiscal multipliers.

Multipliers. As in Blanchard and Perotti (2002), Auerbach and Gorodnichenko (2012, 2013), Chahrour, Schmitt-Grohe, and Uribe (2012) and Caldara and Kamps (2017), we define the fiscal multiplier as the dollar response of output to a shock of size one dollar.

Let $P$ be either the level of fiscal spending $G$ or the level of taxes $T R$ (not in logs); $G D P$ be the level of output (not in logs); $\beta y_{h}$ be the response of log-output at horizon $h$ to a fiscal policy shock; and $\beta p_{0}$ be the impact of the fiscal policy shock to the corresponding fiscal variable expressed in logs. Then, the multiplier is defined as

$$
\mathcal{M} p_{h}=\left(\beta y_{h} / \beta p_{0}\right)(G D P / P)
$$

where $G D P / P$ is a policy shock-specific scaling factor converting elasticities to dollars. As in Caldara and Kamps (2017), we set the scaling factors for the two shocks of interest (unexpected change in fiscal spending and tax revenues) to their sample means on the estimation period, i.e., $(G D P / G)^{-1}=0.20$ and $(G D P / T)^{-1}=0.18$, respectively. ${ }^{20} \mathrm{We}$ consider positive fiscal spending shocks and negative tax shocks to compare multipliers related to shocks expected to have a positive effect on output.

\footnotetext{
${ }^{20}$ This definition of the fiscal multipliers enhances the comparability of our results with those documented by the literature. For a discussion on this vs. alternative definitions, see Ramey (2019).
} 


\section{Results}

Our exercises cover three scenarios. First, we document the empirical findings obtained by relying only on fiscal instruments for the identification of fiscal spending and tax revenues shocks in our model. We then explore the polar opposite case, i.e., the one in which we use only TFP, i.e., a non-fiscal instrument, to identify output shocks in first place and then recover the output effects of fiscal shocks via the moments associated to the covariance matrix of the residuals. A key result is that different assumptions on the correlation between TFP shocks and tax revenues shocks lead to dramatically different estimates of the tax multiplier. Instead, the estimates related to the output effects of fiscal spending shocks are relatively robust across scenarios. We then discuss the link between different estimates of the output-tax elasticity and the corresponding tax multiplier. Finally, we show that our results are robust to estimating fiscal shocks by working with all available instruments in a joint fashion, i.e., we instrument both fiscal and non-fiscal shocks with fiscal and non-fiscal proxies.

\subsection{Fiscal instruments only approach}

Fiscal spending shock: Auerbach and Gorodnichenko's (2012) instrument. We begin our analysis by instrumenting the fiscal spending shock with our novel AG proxy, which is meant to identify unexpected changes in fiscal spending. In this case, $Y_{t}=\left(y_{t}, t r_{t}, g_{t}\right)^{\prime}, Z_{t}=\left(A G_{t}\right)$, and $\varepsilon_{1, t} \equiv \varepsilon_{t}^{g}$, and we estimate an AC-SVAR model for $W_{t}=\left(Y_{t}^{\prime}, Z_{t}\right)^{\prime}=\left(y_{t}, t r_{t}, g_{t}, A G_{t}\right)^{\prime}$, where therefore the last equation pertains to the proxy. While the proxy $A G_{t}$ identifies the fiscal spending shock $\varepsilon_{t}^{g}$, we achieve just identification of all shocks (i.e. also the tax shock and the output shock in $\varepsilon_{2, t} \equiv\left(\varepsilon_{t}^{t r}, \varepsilon_{t}^{y}\right)$ ) by imposing that fiscal spending does not instantaneously respond to output shocks. ${ }^{21}$ For brevity, the maximum likelihood estimates of the $\widetilde{G}$ matrix along with $68 \%$-MBB confidence intervals for the estimated parameters are confined in the Appendix.

Figure 1 (left panel) plots the fiscal spending multiplier obtained from this specification. The on-impact multiplier $\left(\mathcal{M} g_{0}\right.$ in our notation) is about 1.1 , it increases to

\footnotetext{
${ }^{21}$ Formally, this is the constraint $b_{g, y}=0$ discussed in Section 3 (albeit for a different proxy-SVAR). Blanchard and Perotti (2002) impose a zero contemporaneous response of fiscal spending to all shocks affecting output. The two restrictions are equivalent if output is not affected by fiscal shocks at time $t$. If it is, our restriction is less stringent than Blanchard and Perotti's (2002). The difference in these restrictions is due to the fact that they work with an "AB-model" (Lütkepohl (2005)) which accounts also for the contemporaneous relationships among the variables. Differently, we work with a "B-model", which focuses directly on the mapping going from the structural shocks to the VAR innovations.
} 
about 1.6 after two quarters, it stays at that level for about one year, then it gradually declines. The confidence interval associated with the peak multiplier, reported in Table 1, ranges from 1.1 to 2 . While the just identified model cannot be offered formal statistical support by the overidentification restriction test, we notice that the estimated relevance parameter which connects the $A G_{t}$ instrument to the fiscal shock $\varepsilon_{t}^{g}$ is $\widehat{\phi}_{A G}=0.0129$, is strongly significant, and implies a correlation of $96 \%$ with the identified fiscal shock.

Table 1 collects our estimate of the output-spending elasticity, which we recover via the expression $\psi_{y}^{g}=-\left(\widetilde{G I}_{3,1} / \widetilde{G I}_{3,3}\right)$, where $\widetilde{G I} \equiv \widetilde{G}^{-1}$, and $\widetilde{G I}_{i, j}$ is the element located in the $i$-th row and $j$-th column of the $\widetilde{G I}$ matrix. Caldara and Kamps (2017) show that the fiscal policy coefficient $\psi_{y}^{g}$ is negatively related to the fiscal spending multiplier $\mathcal{M} g_{0}$ for values of $\psi_{y}^{g}$ which are below 1.8. We obtain a point estimate of $\hat{\psi}_{y}^{g}=-0.0029$. The associated confidence interval is $(-0.027,0.025)$, and suggests that the population parameter is not statistically different from zero. This finding supports Blanchard and Perotti's (2002) choice of calibrating such elasticity to zero. Caldara and Kamps' (2017) analytical derivations show that a zero elasticity implies an on-impact multiplier equal to 1 , which is in line with what we find.

Tax shock: MR instrument. We now turn to the identification of the tax revenues shock. The instrument we use is the series of unanticipated tax shocks produced by Mertens and Ravn (2011b), which we label $M R$. Since $Y_{t}=\left(y_{t}, t r_{t}, g_{t}\right)^{\prime}, Z_{t}=\left(M R_{t}\right)$ and $\varepsilon_{1, t} \equiv \varepsilon_{t}^{t r}$, we estimate an AC-SVAR model for $W_{t}=\left(Y_{t}^{\prime}, Z_{t}\right)^{\prime}=\left(y_{t}, t r_{t}, g_{t}, M R_{t}\right)^{\prime}$, where the last equation models the instrument $M R_{t}$. In this case $M R_{t}$ identifies directly the tax shock $\varepsilon_{t}^{t r}$ but, consistently with the previous case, we achieve identification of all shocks (i.e. also the fiscal spending shock and the output shock in $\varepsilon_{2, t} \equiv\left(\varepsilon_{t}^{g}, \varepsilon_{t}^{y}\right)$ ) by imposing the restriction that fiscal spending does not instantaneously respond to output shocks.

The point estimate of the relevance parameter for the $M R_{t}$ instrument is $\widehat{\phi}_{M R}=$ 0.043, which implies a correlation of $27 \%$ with the identified tax shock. Figure 1 (right panel) plots the implied tax multiplier. As one can appreciate, this multiplier is large, takes the value of 2.1 on impact $\left(\mathcal{M} t r_{0}\right)$ and a peak value of 3.1 after three quarters. The size of the multiplier is in line with the estimates by Mertens and Ravn (2014) and part of the literature cited therein. The confidence interval for the peak tax multiplier - reported in Table 1 - ranges from 1.4 to 4.8. We then recover the output-tax elasticity as $\psi_{y}^{t r}=-\left(\widetilde{G I}_{2,1} / \widetilde{G I}_{2,2}\right)$. Conditional on the estimated model, the point estimate is 
$\widehat{\psi}_{y}^{t r}=3.36$, close to that reported in Mertens and Ravn (2014) who find it to be equal to 3.13, and to that documented in Mertens and Ravn (2011a), which is equal to 3.7. Moreover, as shown by Caldara and Kamps (2017), our estimate is close to the one resulting from the sign restrictions approach by Mountford and Uhlig (2009), which is 3. Our confidence interval for $\psi_{y}^{t r}$ is $(2.25,4.45)$. Although our intervals reflect some uncertainty about the value of this elasticity, the lower bound remarks that the estimated size is reasonably higher than the value 2.08 used by Blanchard and Perotti (2002), who rely on an application of the OECD methodology documented in Giorno, Richardson, Roseveare, and van den Noord (1995), and is considerably higher than the value 1.7 produced by Follette and Lutz (2010) for the US economy. We postpone the discussion on the plausibility of an output-tax elasticity around 3 to Section 4.3.

\subsection{TFP only approach}

Caldara and Kamps (2017) employ non-fiscal instruments to identify fiscal shocks. They do so by estimating fiscal policy rules first, and then they recover the impulse vector (i.e., the on impact responses of output and fiscal variables) of interest by combining the estimated elasticities with the information coming from the covariance matrix of the VAR residuals. ${ }^{22}$ Following them, we use the Fernald (2014)'s measure of TFP adjusted for factor utilization, $T F P_{t}$, which we use as an instrument for output shocks. While such shocks are not of direct interest for the computation of the fiscal multipliers, the information related to their impulse vector can be fruitfully combined with that of the covariance matrix of our VAR to achieve full identification and recover the output effects of fiscal spending and tax shocks. Thus, we have $Y_{t}=\left(y_{t}, t r_{t}, g_{t}\right)^{\prime}, Z_{t}=\left(T F P_{t}\right)$ and $\varepsilon_{1, t} \equiv \varepsilon_{t}^{y}$, and we estimate an AC-SVAR model for $W_{t}=\left(Y_{t}^{\prime}, Z_{t}\right)^{\prime}=\left(y_{t}, t r_{t}, g_{t}, T F P_{t}\right)^{\prime}$, the last equation of the system pertaining to $T F P_{t}$, with innovation $v_{t}^{T F P}$.

To identify the three structural shocks of the system, we supplement the TFP proxy with the two restrictions $b_{t r, g}=0$ and $b_{g, y}=0$ discussed in Section 3, and summarized in the structure of the matrix $\tilde{G}$ in (14). While $b_{g, y}=0$ (fiscal spending does not instantaneously respond to output shocks) is consistent with the proxy-SVARs estimated in the fiscal instruments only approach, the restriction $b_{t r, g}=0$ (tax revenues does not instantaneously respond to fiscal spending shocks) is necessary for the identification of the model. The proxy-SVAR is overidentified, and the overidentification restrictions test returns a p-value of 0.41 , which leads to not rejecting the model specification. The

\footnotetext{
${ }^{22}$ For an early study on the connection between policy rules and policy shocks with an application to the identification of monetary policy shocks, see Leeper, Sims, and Zha (1996).
} 
point estimate of the relevance parameter is $\widehat{\phi}_{1}=1.86$, which implies a correlation of $57 \%$ with the identified output shock.

As shown by Figure 1, the point estimates of dynamic fiscal spending multipliers identified with TFP shocks turns out to be in line with the ones computed with the AG instrument. The impact multiplier $\left(\mathcal{M} g_{0}\right)$ is equal to 1.1 , while the peak - which occurs after two quarters - is equal to 1.9, and the associated confidence interval ranges from 1.3 to 2.4. The point estimate of the elasticity of fiscal spending to output $\psi_{y}^{g}$ is negative, and zero is not included in the confidence interval (even though the upper bound is very close to zero). Overall, these results are close to those reported in Caldara and Kamps (2017).

Turning to the tax multiplier, we estimate it to be substantially lower that the one obtained with the MR instrument. On impact, the multiplier is estimated to be 0.4 , and the peak value - 0.76 - realizes five quarters after the shock. The confidence interval for the peak tax multiplier ranges from a value slightly less than zero to 0.93 . Figure 1 shows that the drop of the tax multiplier relative to the MR case is substantial for at least 25 quarters after the shock. What is the driver of this drastic change in the tax multiplier when moving from the MR case to the TFP one? Table 1 collects the estimated value

of the tax policy coefficient $\psi_{y}^{t r}$ in this scenario, which is 2.1 , with associated confidence interval $(1.8,2.5)$. The estimated elasticity, as well as the associated confidence interval, is significantly lower than the estimate obtained when using the MR instrument only. The fact that lower values of the tax elasticity, $\psi_{y}^{t r}$, are associated with lower values of the multiplier, $\mathcal{M} t r$, is consistent with the simulations proposed in Mertens and Ravn (2014), and with the analytical derivations documented in Caldara and Kamps (2017).

\subsection{TFP only approach: Relaxing the TFP-tax shocks orthog- onality condition}

Evidence and implications for the multipliers. A crucial assumption behind the case entertained in the previous section is that of orthogonality of the TFP instrument with respect to the fiscal shocks in our proxy-SVAR. Such exogeneity assumption is based on the well-known delays characterizing fiscal spending decisions and implementations (Blanchard and Perotti (2002)). Differently, the assumption of orthogonality between TFP shocks and tax shocks is much more questionable, given that tax revenues are cyclical. Hence, one would expect TFP shocks affecting output to affect also fluctuations in tax revenues. A look at the data offers support to this intuition. Figure 
2 plots the contemporaneous correlations between the VAR residuals of output $\left(\hat{u}_{t}^{y}\right)$, tax revenues $\left(\hat{u}_{t}^{T R}\right)$, and public spending $\left(\hat{u}_{t}^{G}\right)$ on the one hand, and TFP residuals on the other $\left(\hat{v}_{t}^{T F P}\right)$. Such reduced form correlations point to a significant (at a $1 \%$ level) comovement not only between output residuals and TFP, but also between TFP and tax revenues residuals, a necessary condition for the TFP proxy to correlate with tax shocks. Differently, the correlation between TFP and spending residuals is not significantly different from zero. ${ }^{23}$

We interpret the evidence in Figure 2 as supportive of a specification of the form (15), where the TFP jointly serves as an instrument for output shocks and tax shocks. The implication is that extra information from the data can be used to identify tax shocks, output shocks, government spending shocks and, eventually, the fiscal policy multipliers, as implied by the structure of the matrix $\tilde{G}$ in (16) for the "one proxy for two structural shocks scenario". Crucially, the relevance of the TFP instrument for the identification of both output and tax shocks is supported by the data in the sense that the estimated coefficient for the relevance of TFP proxy as an instrument for the output shock is $\widehat{\phi}_{1}=1.63$ and implies a correlation with the output shock of $49.7 \%$, while the estimated coefficient for the relevance of TFP as an instrument for the tax shock is $\widehat{\phi}_{2}=-0.89$ and implies a correlations with the tax shock of $-27 \%$.

What are the implications for the multipliers? The peak fiscal spending multiplier is estimated to be around 2 with confidence interval ranging from 1.4 to 2.6. This figure is slightly larger than, but not statistically different from, those found when imposing the TFP-tax shocks orthogonality condition. Quite differently, the impact on the tax multiplier is dramatic, its peak value moving from 0.7 to 3.6. This latter figure is statistically in line with the tax multiplier around 3 estimated with the $M R$ instrument.

Statistical support to the relaxation of the TFP-tax shocks orthogonality condition. Our results show that relaxing the orthogonality condition $\phi_{2}=$ $\operatorname{Cov}\left(v_{t}^{T F P}, \varepsilon_{t}^{t r}\right)=0$ makes a key difference as regards the size of the estimated tax multiplier. The confidence interval for $\phi_{2}$ is $(-1.51,-0.64)$. Mapped into the correlation

\footnotetext{
${ }^{23}$ Caldara and Kamps (2017) assess the exogeneity of the TFP instrument by regressing it over Mertens and Ravn's (2011) narrative measure of tax shocks and Ramey's (2011) narrative measure of expected exogenous changes in military spending. They document individually and jointly insignificant estimated coefficients, and conclude that the TFP instrument is exogenous. After replicating their estimates, we verified that, when computing HAC standard errors, the t-statistic of the estimated coefficient of the measure of tax shocks increases from 1.53 to 1.92 , while the F-statistic goes from 1.44 up to 1.88. The use of HAC standard errors in the regression for the TFP instrument is motivated by the significant first-order autocorrelation in the disturbances.
} 
with the identified tax shock, this implies values in the range $(-40 \%,-19.5 \%)$. Notably, for each fixed value $\phi_{2}=\breve{\phi}_{2}$, the proxy-SVAR is overidentified, hence testable by the overidentification restrictions test. We conduct such test by proceeding as follows. We consider three guess values of the parameter $\phi_{2}$ which belong to the estimated $68 \%$ confidence interval. The values we consider are: i) $\breve{\phi}_{2}=-1.51$, which corresponds to the lower bound of the confidence interval; $\breve{\phi}_{2}=-1$ (central value of the confidence interval); and $\breve{\phi}_{2}=-0.64$ (upper bound of the confidence interval). The p-values associated with the overidentification restrictions test in these three cases are $0.25,0.87$ and 0.75 , respectively. Hence, the data support the proxy-SVAR where the TFP proxy simultaneously correlate with output and tax shocks. Admittedly, allowing for this nonzero correlation does not come without costs. The confidence interval for the peak tax multiplier ranges from 0.2 to 5.9 , hence it tends to be larger relative to the confidence interval obtained with the $M R_{t}$ instrument alone. We will discuss this issue in more depth when we present the results obtained when using multiple instruments.

Driver of the large tax multiplier. What is the driver of the substantial difference between the small tax multiplier found when imposing the TFP-tax shocks orthogonality and the one around 3 obtained by relaxing such restriction? Mertens and Ravn (2014) and Caldara and Kamps (2017) document the mapping between the output-tax elasticity and the tax multiplier. In particular, Caldara and Kamps (2017) derive an analytical expression for the tax multiplier and show that, if $\psi_{y}^{t r} \in(-1,4)$ range, there is a positive correlation between the elasticity and the multiplier. Table 1 documents the substantial change in such elasticity when the TFP-tax shocks orthogonality is relaxed, with $\widehat{\psi}_{y}^{t r}$ moving from 2.1 (orthogonality imposed) to 3.8 (non orthogonality allowed). This latter number is pretty close to the 3.7 estimate provided by Mertens and Ravn (2011a), who employ long run restrictions to identify movements in output due to a technology shock to tackle the tax-output endogeneity bias. Moreover, the associated confidence interval $(2.3,4.9)$ implies that estimates around 3 that are often found in the literature are statistically equivalent to ours. Our Appendix formally shows the downward bias that affects the estimate of the output-tax elasticity if the econometrician misses to model the correlation between TFP and tax shocks in a world in which such correlation is actually present.

Output-tax elasticity equal to 3: How sensible? As stated above, Blanchard and Perotti (2002) rely on an output-tax elasticity equal to 2.08, which is the one estimated by the OECD (Giorno, Richardson, Roseveare, and van den Noord (1995)). Such 
elasticity is slightly larger than that estimated by Follette and Lutz (2010) on yearly data (1.7). Instead, our results rely upon output-tax elasticities equal to 3 or larger. Are such large elasticities sensible? Mertens and Ravn (2014) critically review the construction of output-tax elasticity by the OECD, which is a weighted average of the output elasticities for different tax revenue components (personal income taxes, social security contributions, indirect taxes and corporate income taxes). Each component-specific elasticity is a product of two elasticities, i.e., the tax base-tax revenues one and the output-tax base one. Mertens and Ravn (2014) point out that, while both elasticities are (somewhat necessarily) computed by relying on many questionable assumptions, the second one in particular is typically estimated via OLS regressions that do not tackle the obvious endogeneity issue affecting the output-tax relationship. Importantly, Mertens and Ravn (2014) show that such endogeneity issue is likely to induce a negative bias in the estimated output-tax elasticity. As pointed out above, Mertens and Ravn (2011a) tackle this bias by estimating the response of the US federal tax revenues to a technology shock identified with long run restrictions, and find a value for the elasticity equal to 3.7. Caldara and Kamps (2017) derive the output-tax elasticity implied by the sign restriction approach pursued by Mountford and Uhlig (2009), and find a value equal to 3. Overall, a value of the output-tax elasticity equal to 3 or larger does not seem at odds with the US data.

\subsection{Multiple instruments approach}

As stressed in the Introduction and in Section 3, the AC-VAR methodology we work with allows us to jointly employ multiple instruments. We then combine all instruments used so far (both fiscal and non-fiscal) and re-estimate both multipliers. This way to proceed adds further moment conditions and, therefore, information (if the moment conditions are supported by the data). Formally, we work with $Y_{t}=\left(y_{t}, t r_{t}, g_{t}\right)^{\prime}$, $Z_{t}=\left(A G_{t}, M R_{t}, T F P_{t}\right)$, and we estimate an AC-SVAR model for $W_{t}=\left(Y_{t}^{\prime}, Z_{t}^{\prime}\right)^{\prime}=$ $\left(y_{t}, t r_{t}, g_{t}, M R_{t}, A G_{t}, T F P_{t}\right)^{\prime}$. To our knowledge, this is the first instance in the proxySVAR literature in which the number of employed external instruments $k$ is the same as the number of variables $n$ the original SVAR comprises, i.e., all shocks in the VAR are instrumented.

Given the role played by the TFP-tax shocks orthogonality condition for the estimation of the tax multiplier, we analyze two cases, one in which we impose the orthogonality condition, and the other one in which we do not. 


\section{Fiscal shocks: AG \& MR \& TFP instruments - orthogonality condition.}

Figure 3 shows the fiscal spending and tax multipliers generated with the AC-SVAR model with multiple instruments. The fiscal spending multiplier peaks at a value equal to 1.8, which is relatively similar to those found in the one-instrument scenarios. Again, this multiplier is precisely estimated as the associated confidence interval ranges from 1.3 to 2.2. The peak realization of the tax multiplier is 1 , with associated confidence interval ranging from 0.4 to 1.3 . While being larger that the one estimated with the TFP instrument only under the assumption of TFP-tax shocks orthogonality (0.76), this values is three times smaller than the one obtained with the TFP instrument only when the orthogonality condition is relaxed. Hence, the two findings as far as the tax multiplier is concerned are: i) fiscal instruments positively affect the tax multiplier from a quantitative standpoint; ii) such multiplier is much lower than the one documented in the non-orthogonality case. From a statistical standpoint, this model - which is overidentified - is supported by the data, the p-value of the overidentification restriction test being 0.72 .

Fiscal shocks: AG \& MR \& TFP instruments - non orthogonality. A natural question is what happens if we relax the TFP-tax shocks orthogonality condition when playing with multiple instruments. Figure 3 documents the spectacularly different implications for the two multipliers. The impact of relaxing the orthogonality condition on the estimated fiscal spending multiplier is virtually zero, i.e., the multiplier is exactly the same as the one estimated when imposing such condition. Differently, the tax multiplier records a peak value of 2.8 vs. the value of 1 estimated when imposing the orthogonality condition; the associated confidence interval ranges from 0.4 to 4.3. Figure 3 shows that the estimated tax multiplier under non-orthogonality is clearly not contained by the confidence interval surrounding the point estimates of the tax multiplier conditional on the assumption of orthogonality. As before, the driver of this dramatic increase of the value of the tax multiplier under non-orthogonality is the impact of the orthogonality/non-orthogonality assumption on the estimated outputtax elasticity, which moves from 2.3 (orthogonality imposed) to 3.3 (orthogonality not imposed). Turning to the output-fiscal spending elasticity, our model allows us to estimate it jointly with the rest of the system. Our point estimate, which is zero, lends once again support to the Blanchard and Perotti (2002) zero restriction typically used in this literature. Finally, this AC-SVAR model estimated with multiple instruments and the relaxation of the TFP-tax shocks orthogonality condition is overidentified and supported by the data with a p-value of 0.89 . 
Also in this case, a note on the uncertainty surrounding our tax multiplier estimates conditional on the non-orthogonality case is in order. While the empirical analysis points to a non-zero correlation between the TFP proxy and the tax shock, we observe that the uncertainty surrounding the point estimates of the tax multiplier is much larger in this case than when orthogonality is imposed. In this respect, the estimated tax multiplier appears less robust than the estimated fiscal spending multiplier. This evidence confirms that the endogeneity issue involved with the identification of the US tax shock is more severe than the endogeneity issue involved with the identification of the US fiscal spending shock.

\section{Robustness checks}

Monetary policy. Our baseline model is a fiscal policy-only model. Research on the fiscal-monetary policy mix shows that the output effects of fiscal shocks are importantly affected by the systematic monetary policy in place (see Leeper (1991) for an early contribution, and Leeper and Leith (2016) for a recent review). To control for the role of monetary policy, we work with an enriched model featuring also CPI inflation $\left(\pi_{t}\right)$ and the 3 -month Treasury bill rate $\left(r_{t}\right)$. Hence, our vector of modeled variables becomes $Y_{t}=\left(y_{t}, t r_{t}, g_{t}, \pi_{t}, r_{t}\right)^{\prime}$. We estimate this model by augmenting the set of instruments employed so far (AG, MR, and TFP) with the measure of oil shocks (OIL) proposed by Hamilton (2003) as an instrument for the inflation shock, as done by Caldara and Kamps (2017). ${ }^{24}$ Hence, we estimate an AC-SVAR model for $W_{t}=\left(Y_{t}^{\prime}, Z_{t}^{\prime}\right)^{\prime}=\left(y_{t}, t r_{t}, g_{t}, \pi_{t}, r_{t}, M R_{t}, A G_{t}, T F P_{t}, O I L_{t}\right)^{\prime}$. As in the previous sections, we study two different scenarios, one in which the TFP-tax shocks orthogonality condition is imposed, and one in which it is relaxed.

Figure 4 shows the estimated multipliers in these two scenarios. As before, the estimated fiscal spending multiplier is insensitive to the treatment of the orthogonality condition, and peaks at a value equal to 1.8 with relatively tight confidence interval ranging from 1.5 to 2.3. Quite differently, the peak of the tax multiplier varies substantially,

\footnotetext{
${ }^{24}$ Caldara and Kamps (2017) also employ the measure of monetary policy shocks proposed by Romer and Romer (2004) to instrument the policy rate in their fiscal rules. We avoid using such instrument because it is not available before 1969. This would reduce our sample by about 20 years. We notice that the results we obtain with the model with inflation and the policy rate and very similar to our baseline ones. Caldara and Kamps (2017) reach the same conclusion. Evans (1992) find that TFP measures produced with the Solow-Prescott residuals approach are Granger-caused by monetary measures. The correlation between TFP shocks and Romer and Romer's (2004) measure of monetary policy shocks is low (0.07) and not significant at conventional levels.
} 
and is approximately 1.1 when the condition is imposed, while it jumps to 3.1 when the orthogonality condition is not imposed. It is important to stress that this latter model, which is again overidentified, is supported by the overidentification restrictions test which delivers a p-value of 0.99. For this proxy-SVAR, the estimated coefficient for the relevance of TFP proxy as an instrument for the output shock is $\widehat{\phi}_{1}=1.69$ and implies a correlation with the output shock of $51.5 \%$, while the estimated coefficient for the relevance of TFP as an instrument for the tax shock is $\widehat{\phi}_{2}=-0.64$ (with associated confidence interval equal to $(-0.98,-0.46))$ and implies a correlations with the tax shock of $-19 \%$. Overall, these empirical results tend to confirm those documented in the previous sections with a more parsimonious VAR.

Fiscal foresight. Anticipation effects are likely to be of great relevance for the identification and transmission of fiscal policy shocks. This phenomenon, often referred to as "fiscal foresight", makes SVAR analysis complicated. Standard VARs, which rely on current and past shocks to interpret the dynamics of the modeled variables, can be "non-fundamental", in that they do not embed the information related to "news shocks", i.e., future shocks anticipated by rational agents. Leeper, Walker, and Yang (2013) work with different fiscal models and show that the anticipation of tax policy shocks severely affects VAR exercises aiming at identifying fiscal shocks. Ramey (2011) shows that government spending shocks estimated with standard fiscal SVARs are predictable, i.e., they are non-fundamental. Forni and Gambetti (2014) propose a test for "sufficient information" to detect non-fundamentalness that is based on checking the predictability of the VAR shocks of interest with information external to the VAR. We implement their test by regressing the identified fiscal shocks against lagged realizations of the factors extracted from the large set of macroeconomic and financial variables put together by McCracken and $\mathrm{Ng}(2016) .{ }^{25}$ We use two sets of regressors: i) the first estimated factor, which explains about $55 \%$ of the variance of the data; ii) the first four factors, which explain almost 90\%. Table 2 collects the p-values of the F-tests for information sufficiency we run over all our models. For each shock or combination of shocks, we consider two scenarios: a) an univariate scenario in which each fiscal shock is regressed over a constant and the estimated factors (first two rows of each shock/combination of shocks); b) a multivariate one in which the vector of

\footnotetext{
${ }^{25}$ To maximize the number of observations to compute the factors, we work with monthly data. We convert monthly factors in quarterly ones by taking the last realization of the factors in each quarter. Given that the factors are estimated with a sample starting in 1959, our regressions regard the sample 1959-2006.
} 
fiscal shocks is regressed over constants and the estimated factors (last row of each shock/combination of shocks). All models pass the information sufficiency test. ${ }^{26}$

\section{Conclusions}

This paper estimates US government spending and tax multipliers using a flexible proxySVAR approach. Our model allows to: i) relax and test the orthogonality condition according to which proxies must be uncorrelated with non-instrumented structural shocks; ii) use multiple instruments to jointly identify multiple shocks.

We estimate the fiscal spending multiplier to be about 1.6-2.1, no matter what the model specification and the set of fiscal and non fiscal instruments are. Differently, we find the tax multiplier to be 3.1 when a tax instrument only is employed, while its estimate drops to 0.7 when TFP is used as an instrument to estimate the effects of output shocks, and the tax multiplier is then recovered via the moments associated to the covariance matrix of the VAR residuals. We show that these different estimates, which replicate those obtained by key contributions in the literature, are due to the imposition of the TFP-tax shocks orthogonality condition when TFP is used as an instrument. When we relax such assumption, we find a peak tax multiplier that ranges from 2.8 to 3.6 across a set of proxy-SVARs with 3.1 being the estimate favored by the data. Crucially, we show that the relaxation of this orthogonality condition is formally supported by the data. However, our tax multipliers tend to be surrounded by larger statistical uncertainty relative to what we document for the fiscal spending multiplier. These findings are robust to the joint use of fiscal and non-fiscal instruments, and to enlarging the system to account for the role of monetary policy.

From a modeling standpoint, our estimates confirm the positive relationship between changes in the output-tax elasticity and variations in the tax multiplier previously detected via counterfactual simulations by Mertens and Ravn (2014) and analytically worked out by Caldara and Kamps (2017). Policy-wise, our paper unveils a trade-off fiscal policymakers might have to face when designing their fiscal plans. On the one hand, our point estimates point to a tax multiplier larger than the spending one. On the other hand, the former is surrounded by a larger statistical uncertainty. Hence, policymakers with an aversion towards parameter uncertainty may want to assign a

\footnotetext{
${ }^{26}$ Canova and Sahneh (2018) note that Granger-causality tests might over-reject fundamentalness because of aggregation issues affecting the variables modeled with the VAR. The Forni and Gambetti (2014) tests we conducted over the different specifications of our VARs never reject fundamentalness. Hence, our VARs are not subject to the Canova-Sahneh critique.
} 
larger weight to the fiscal spending lever than to taxes. We see the study of optimal fiscal policy under parameter uncertainty as the natural continuation of this research agenda.

\section{References}

Alesina, A., C. A. Favero, and F. Giavazzi (2018): "What Do We Know About the Effects of Austerity?," American Economic Association Paper \&6 Proceedings, $108,524-530$.

(2019): "Effects of Austerity: Expenditure- and Tax-based Approaches," Journal of Economic Perpectives, 33(2), 141-162.

Angelini, G., and L. FAnelli (2019): "Exogenous uncertainty and the identification of Structural Vector Autoregressions with external instruments," Journal of Applied Econometrics, forthcoming.

Arias, J. E., J. F. Rubio-Ramírez, and D. F. Waggoner (2018): "Inference Based on SVARs Identified with Sign and Zero Restrictions: Theory and Applications," Econometrica, 86(2), 685-720.

Auerbach, A., and Y. Gorodnichenko (2012): "Measuring the Output Responses to Fiscal Policy," American Economic Journal: Economic Policy, 4(2), 1-27.

Auerbach, A., and Y. Gorodnichenko (2013): "Output Spillovers from Fiscal Policy," American Economic Review Papers and Proceedings, 103(3), 141-146.

Bachmann, R., And E. Sims (2012): "Confidence and the transmission of government spending shocks," Journal of Monetary Economics, 59(3), 235-249.

Barro, R. J., and C. J. Redlick (2011): "Macroeconomic Effects from Government Purchases and Taxes," Quarterly Journal of Economics, 126(1), 51-102.

Ben Zeev, N., and E. Pappa (2017): "Chronicle of a War Foretold: The Macroeconomic Effects of Anticipated Defense Spending Shocks," Economic Journal, 127, $1568-1597$.

Blanchard, O., and R. Perotti (2002): "An Empirical Characterization of the Dynamic Effects of Changes in Government Spending and Taxes on Output," Quarterly Journal of Economics, 117(4), 1329-1368.

Brüggemann, R., C. Jentsch, and C. Trenkler (2016): "Inference in VARs with conditional volatility of unknown form," Journal of Econometrics, 191, 69-85.

Caggiano, G., E. Castelnuovo, V. Colombo, and G. Nodari (2015): "Estimating Fiscal Multipliers: News From a Nonlinear World," Economic Journal, 125(584), $746-776$.

Caldara, D., and C. Kamps (2017): "The Analytics of SVARs: A Unified Framework to Measure Fiscal Multipliers," Review of Economic Studies, 84, 1015-1040.

Canova, F., and E. Pappa (2007): "Price differentials in monetary unions: The role of fiscal shocks," Economic Journal, 117, 713-737. 
Canova, F., And M. H. Sahneh (2018): "Are Small-Scale SVARs Useful for Business Cycle Analysis? Revisiting Nonfundamentalness," Journal of the European Economic Association, 6(4), 1069-1093.

Chahrour, R., S. Schmitt-Grohe, and M. Uribe (2012): "A Model-Based Evaluation of the Debate on the Size of the Tax Multiplier," American Economic Journal: Economic Policy, 4(2), 28-45.

Christiano, L. J., M. Eichenbaum, and S. Rebelo (2011): "When is the Government Spending Multiplier Large?," Journal of Political Economy, 119(1), 78-121.

Evans, C. L. (1992): "Productivity Shocks and Real Business Cycles," Journal of Monetary Economics, 29(2), 191-208.

Favero, C. A., and F. Giavazzi (2012): "Measuring Tax Multipliers: The Narrative Method in Fiscal VARs," American Economic Journal: Economic Policy, 4(2), 6994 .

Fernald, J. (2014): "A Quarterly, Utilization-Adjusted Series on Total Factor Productivity," Federal Reserve Bank of San Francisco Working Paper No. 2012-19.

Fisher, J. D. M., and R. Peters (2010): "Using Stock Returns to Identify Government Spending Shocks," Economic Journal, 120(544), 414-436.

Follette, G., And B. F. Lutz (2010): "Fiscal Policy in the United States: Automatic Stabilizers, Discretionary Fiscal Policy Actions, and the Economy," Board of Governors of the Federal Reserve System Finance and Economics Discussion Series 2010-43.

Forni, M., And L. Gambetti (2014): "Sufficient information in structural VARs," Journal of Monetary Economics, 66, 124-136.

(2016): "Government Spending Shocks in Open Economy VARs," Journal of International Economics, 99, 68-84.

Ghassibe, M., and F. Zanetti (2019): "State Dependence of Fiscal Multipliers: The Source of Fluctuations Matters," University of Oxford, mimeo.

Giorno, C., P. Richardson, D. Roseveare, and P. van den Noord (1995): "Estimating Potential Output, Output Gaps, and Structural Budget Balances," OECD Economics Department Working Paper No. 152.

Hamilton, J. D. (2003): "What Is an Oil Shock?," Journal of Econometrics, 113, $363-398$.

International Monetary Fund (2020): "World Economic Outlook: The Great Lockdown," April.

Jentsch, C., And C. K. Lunsford (2019a): "Asymptotically Valid Bootstrap Inference for Proxy SVARs," Federal Reserve Bank of Cleveland Working Paper No. 19-08.

Jentsch, C., And K. G. Lunsford (2019b): "The dynamic effects of personal and corporate income tax changes in the United States: Comment," American Economic Review, forthcoming. 
LeEPeR, E. (1991): 'Equilibria Under 'Active' and 'Passive' Monetary and Fiscal Policies," Journal of Monetary Economics, 27, 129-147.

Leeper, E. M., And C. Leith (2016): "Understanding Inflation as a Joint MonetaryFiscal Phenomenon," in: J.B. Taylor and H. Uhlig (Eds.): Handbook of Macroeconomics, Elsevier Science, forthcoming.

Leeper, E. M., C. Sims, and T. Zha (1996): "What Does Monetary Policy Do?," Brookings Papers on Economic Activity, 27, 1-78.

Leeper, E. M., N. Traum, and T. B. Walker (2017): "Clearing Up the Fiscal Multiplier Morass," American Economic Review, 107(8), 2409-2454.

Leeper, E. M., T. B. Walker, and S.-C. S. Yang (2013): "Fiscal Foresight and Information Flows," Econometrica, 81(3), 1115-1145.

LÜtkepohl, H. (2005): "New Introduction to Multiple Time Series Analysis," Springer-Verlag, Berlin and Heidelberg.

McCracken, M. W., And S. NG (2016): "FRED-MD: A Monthly Database for Macroeconomic Research," Journal of Business and Economic Statistics, 34(4), 574589.

Mertens, K., and J. L. Montiel Olea (2018): "Marginal Tax Rates and Income: New Time Series Evidence," Quarterly Journal of Economics, 133(4), 1803-1884.

Mertens, K., And M. Ravn (2019): "The dynamic effects of personal and corporate income tax changes in the United States: Reply to Jentsch and Lunsford," American Economic Review, forthcoming.

Mertens, K., and M. O. Ravn (2011a): "Technology-hours redux: Tax changes and the measurement of technology," NBER International Seminar of Macroeconomics, $41-76$.

(2011b): "Understanding the Aggregate Effects of Anticipated and Unanticipated Tax Policy Shocks," Review of Economic Dynamics, 14(1), 27-54.

(2012): "Empirical evidence on the aggregate effects of anticipated and unanticipated US tax policy shocks," American Economic Journal: Economic Policy, 4(2), $214-237$.

(2013): "The Dynamic Effecs of Personal and Corporate Income Tax Changes in the United States," American Economic Review, 103(4), 1212-1247.

(2014): "A Reconciliation of SVAR and Narrative Estimates of Tax Multipliers," Journal of Monetary Economics, 68, S1-S19.

Mountford, A., and H. Uhlig (2009): "What Are the Effects of Fiscal Policy Shocks?," Journal of Applied Econometrics, 24, 960-992.

Olea, J. M., J. Stock, and M. Watson (2020): "Inference in SVARs identified with an external instrument," Journal of Econometrics, forthcoming.

Perotti, R. (2012): "The effects of tax shocks on output: Not so large, but not so small either," American Economic Journal: Economic Policy, 4(2), 241-237. 
Plagborg-Møller, M., and C. K. Wolf (2018): "Local Projections and VARs Estimate the Same Impulse Responses," Princeton University, mimeo.

Ramey, V. A. (2011): "Identifying Government Spending Shocks: It's All in the Timing," Quarterly Journal of Economics, 126(1), 1-50.

(2019): "Ten Years after the Financial Crisis: What Have We Learned from the Renaissance in Fiscal Research?," Journal of Economic Perpectives, 33(2), 89-114.

Ramey, V. A., and S. Zubairy (2018): "Government Spending Multipliers in Good Times and in Bad: Evidence from U.S. Historical Data," Journal of Political Economy, 126(2), 850-901.

Ricco, G. (2016): "A New Identification of Fiscal Shocks Based on the Information Flow," London Business School, mimeo.

Romer, C., And D. Romer (2004): "A New Measure of Monetary Policy Shocks: Derivation and Implications," American Economic Review, 94(4), 1055-1084.

Romer, C. D., And D. H. Romer (2010): "The Macroeconomic Effects of Tax Changes: Estimates Based on a New Measure of Fiscal Shocks," American Economic Review, 100(3), 763-801.

Rubio-Ramírez, J. F., D. F. Waggoner, and T. Zha (2010): "Structural Vector Autoregressions: Theory of Identification and Algorithms for Inference," Review of Economic Studies, 77, 665-696.

Sims, E., And J. Wolff (2018): "The State-Dependent Effects of Tax Shocks," European Economic Review, 107, 57-85.

Stock, J., and M. W. Watson (2018): "Identification and Estimation of Dynamic Causal Effects in Macroeconomics Using External Instruments," Economic Journal, $128,917-948$.

Stock, J. H., And M. W. Watson (2012): "Disentangling the Channels of the 20072009 Recession," Brookings Papers on Economic Activity, Spring, 81-135.

Wieland, J. F. (2018): "State-dependence of the Zero Lower Bound Government Spending Multiplier," available at https://sites.google.com/site/johannesfwieland/.

Zidar, O. M. (2019): "Tax Cuts for Whom? Heterogeneous Effects of Income Tax Changes on Growth and Employment," Journal of Poltical Economy, forthcoming. 


\begin{tabular}{lcccc}
\hline \hline \multicolumn{1}{c}{ Instruments } & $\psi_{y}^{g}$ & $\psi_{y}^{t r}$ & $\mathcal{M g}$ & $\mathcal{M} t r$ \\
\hline AG only & -0.0029 & - & 1.6531 & - \\
MR only & $(-0.0275 ; 0.0245)$ & & $(1.1518 ; 2.0546)$ & 3.0863 \\
TFP only - orth. & - & 3.3615 & - & $(1.4182 ; 4.8065)$ \\
& -0.1434 & 2.1142 & 1.9134 & 0.7583 \\
TFP only - non orth. & $(-0.2446 ;-0.0441)$ & $(1.8285 ; 2.4671)$ & $(1.2678 ; 2.3752)$ & $(-0.0015 ; 0.9313)$ \\
& -0.3430 & 3.8566 & 2.1842 & 3.5831 \\
AG \& MR \& TFP - orth. & $(-0.4398 ;-0.1192)$ & $(2.3135 ; 4.9939)$ & $(1.3902 ; 2.5508)$ & $(0.2393 ; 5.8781)$ \\
AG \& MR \& TFP - non orth. & -0.0053 & 2.3115 & 1.7885 & 1.0409 \\
AG \& MR \& TFP \& OIL - orth. & $(-0.0295 ; 0.0214)$ & $(2.0936 ; 2.6435)$ & $(1.3421 ; 2.2185)$ & $(0.3851 ; 1.2642)$ \\
& -0.0052 & 3.3487 & 1.7826 & 2.8299 \\
AG \& MR \& TFP \& OIL - non orth. & $-0.0293 ; 0.0220)$ & $(2.4437 ; 4.3210)$ & $(1.2885 ; 2.1725)$ & $(0.3795 ; 4.2754)$ \\
& -0.0175 & 2.6225 & 1.8062 & 1.0586 \\
& $(-0.0497 ; 0.0014)$ & $(2.5275 ; 4.8102)$ & $(1.4892 ; 2.3558)$ & $(0.6505 ; 4.9533)$ \\
\hline \hline
\end{tabular}

Table 1: Estimated elasticities and multipliers: Data in log-levels. Bootstrapped (16th,84th) percentiles below point estimates based on1,000 repetitions and the Moving Block-Bootstrap method. Multipliers: Peak values. 


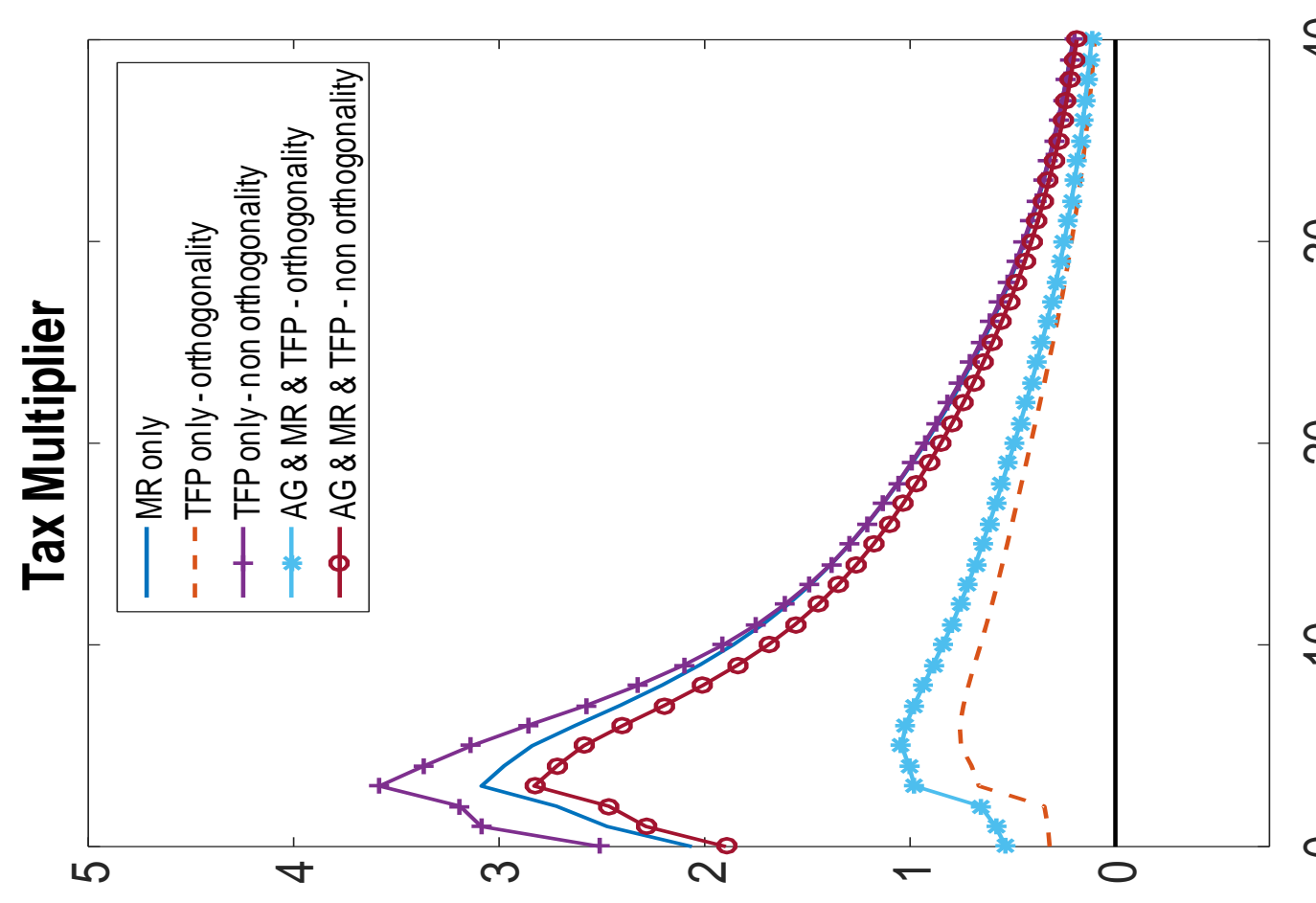

우

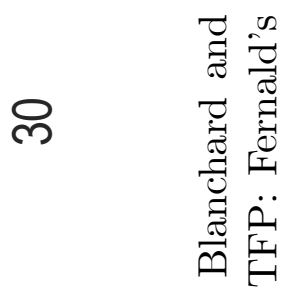

욤

总要

으

离.

so क्ष

寻

कํำ

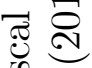

婙

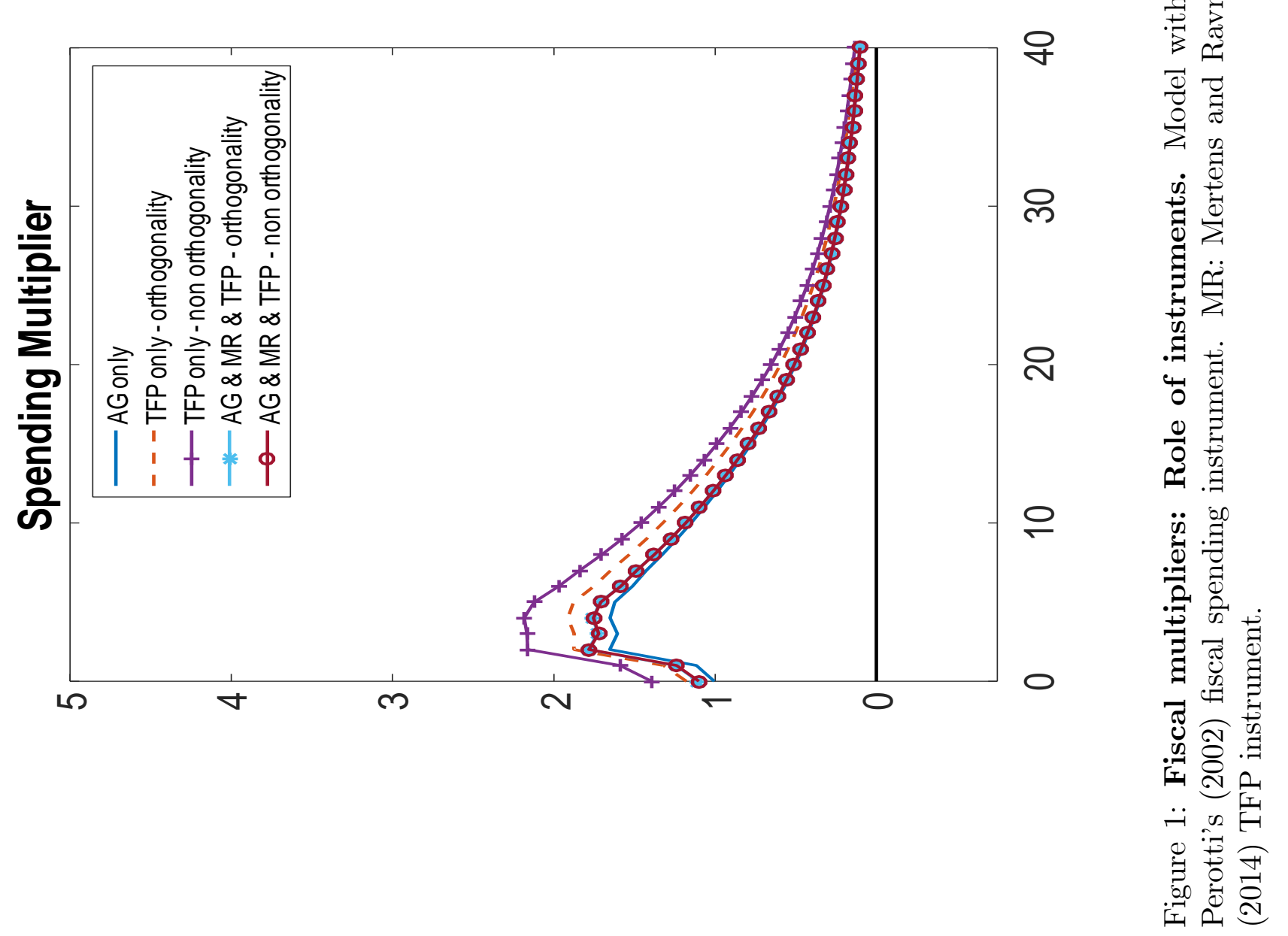




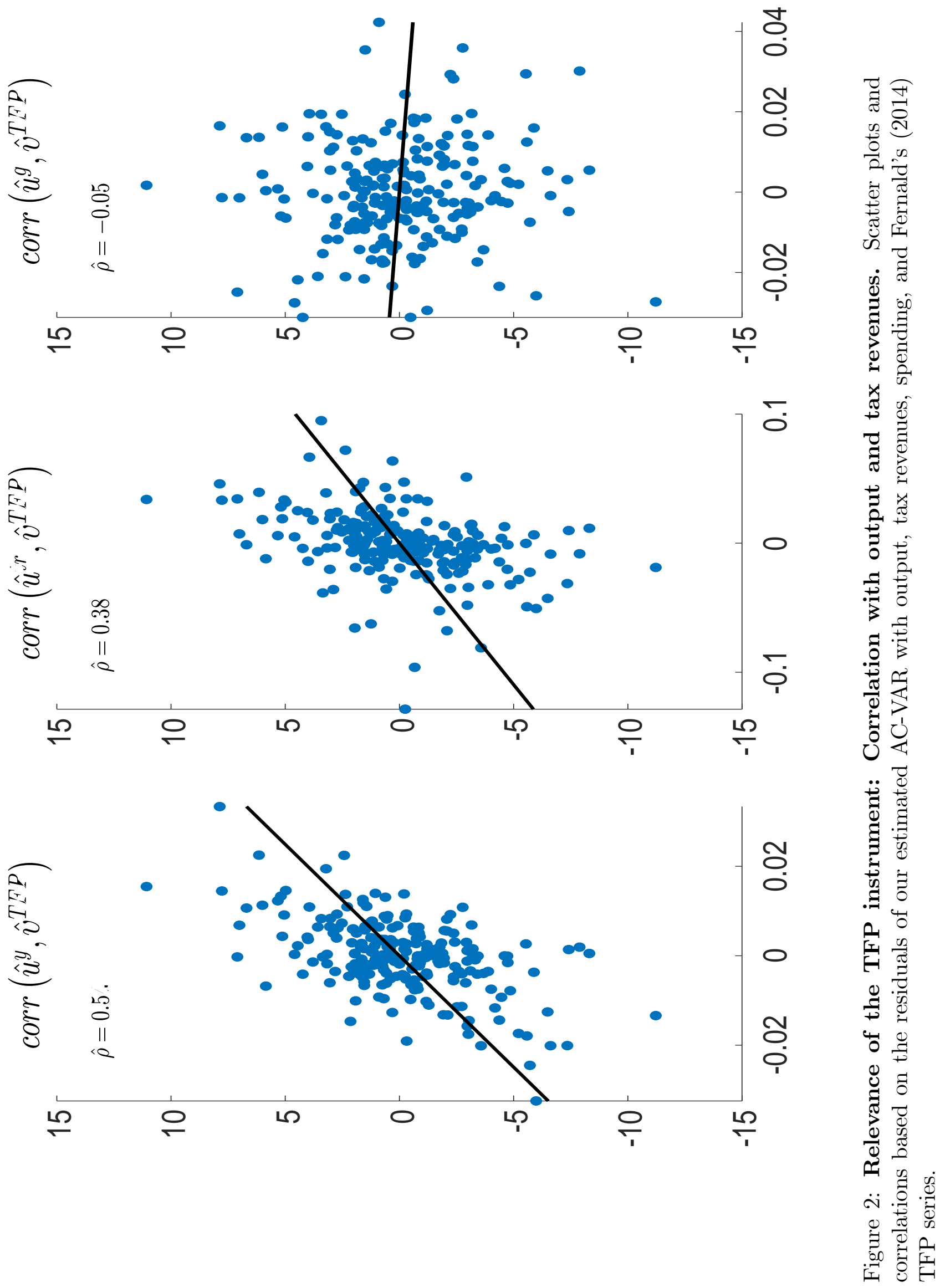




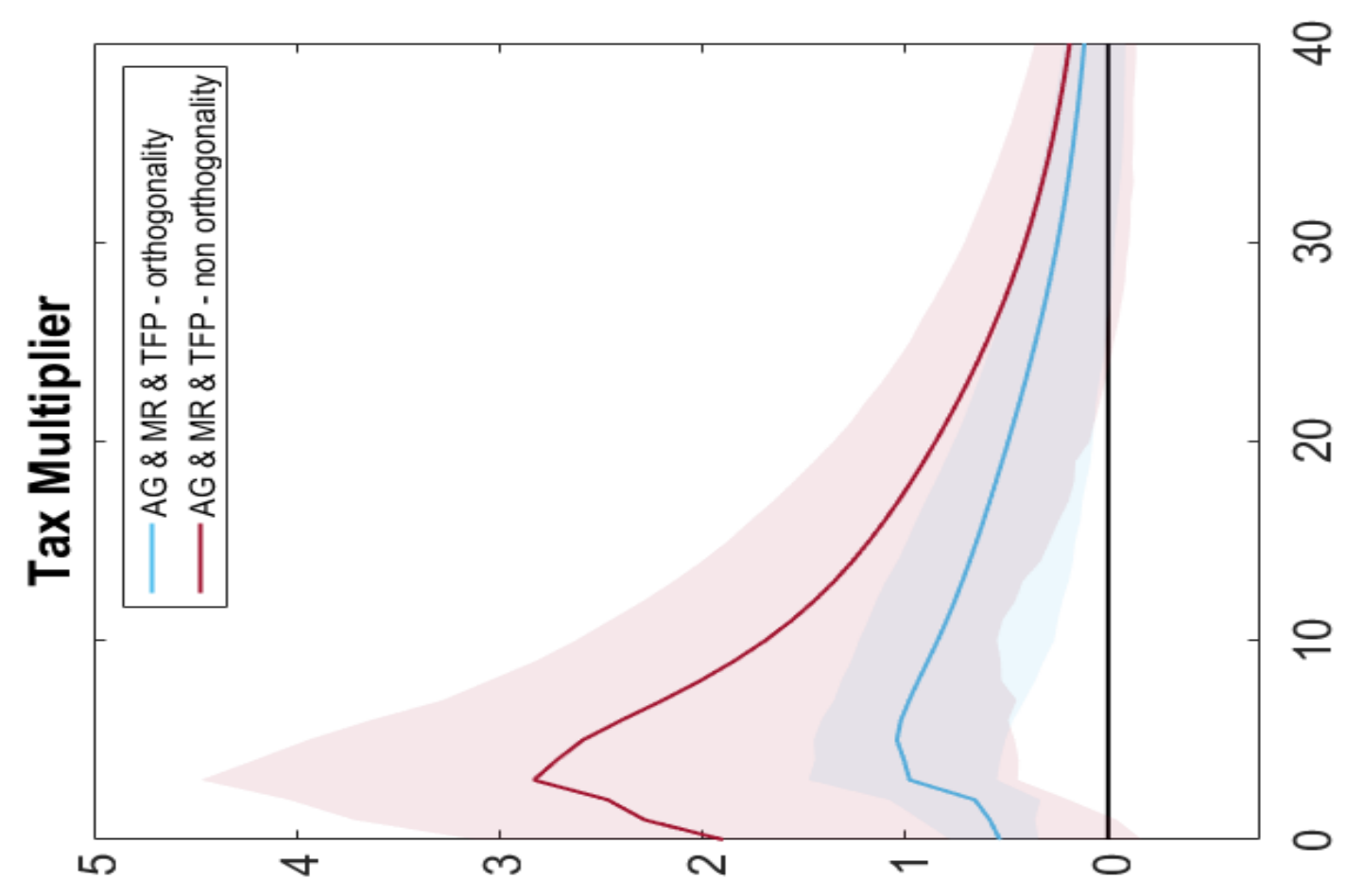

ㅇ

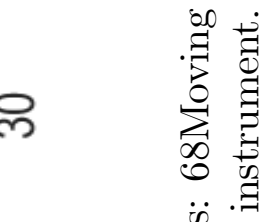

ㄱ.

范

है

过

i 进

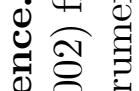

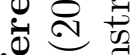

\& $\backsim$

宁厍

نำ

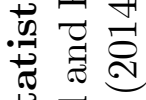

茎 䒕

定苛

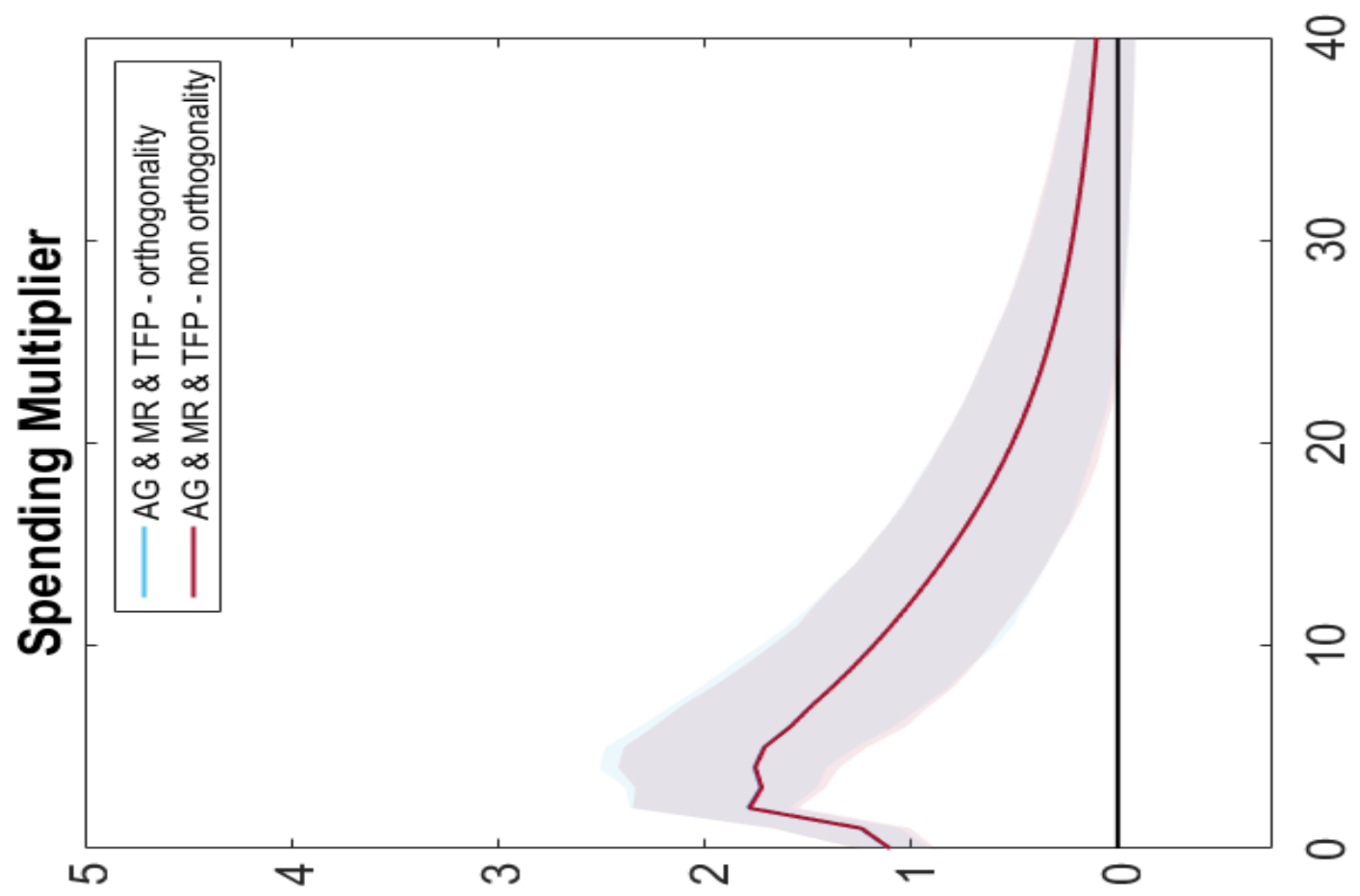

过 $\vec{D}$

密泀穴

$\therefore$ के

ल

용 छ

记

0

일

ㅇ

ฮี

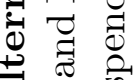

ฮี

步

- $\stackrel{0}{0}$

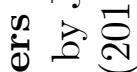

명

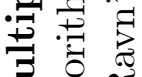

छ

ซี ซิ ซี 出

$\ddot{0}$

०

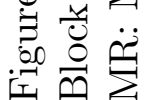




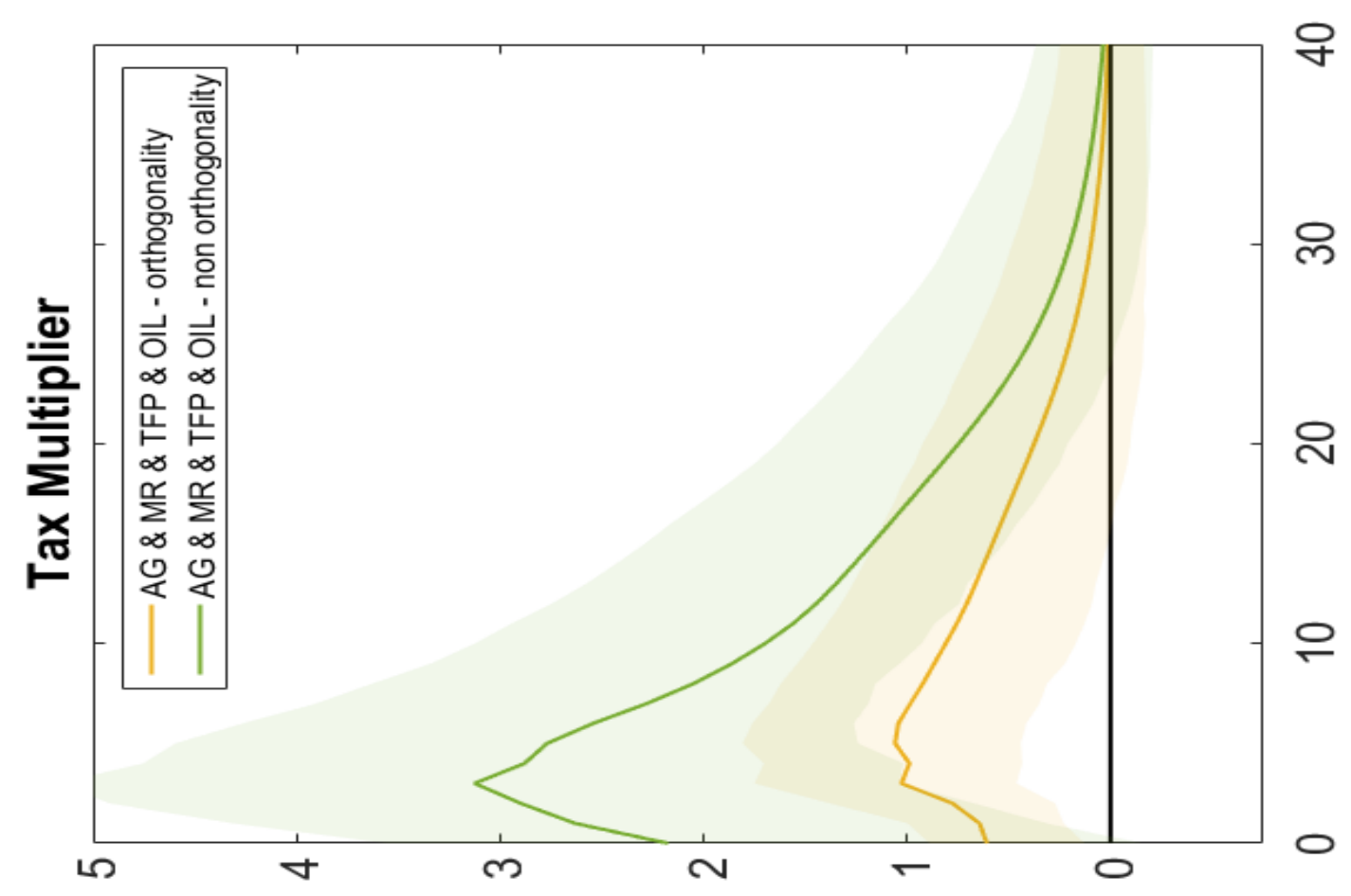

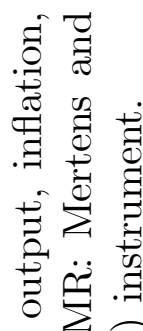

के कू

范

so

吾苛

20

क $凵$

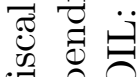

过

舜苞

ชิ

刍

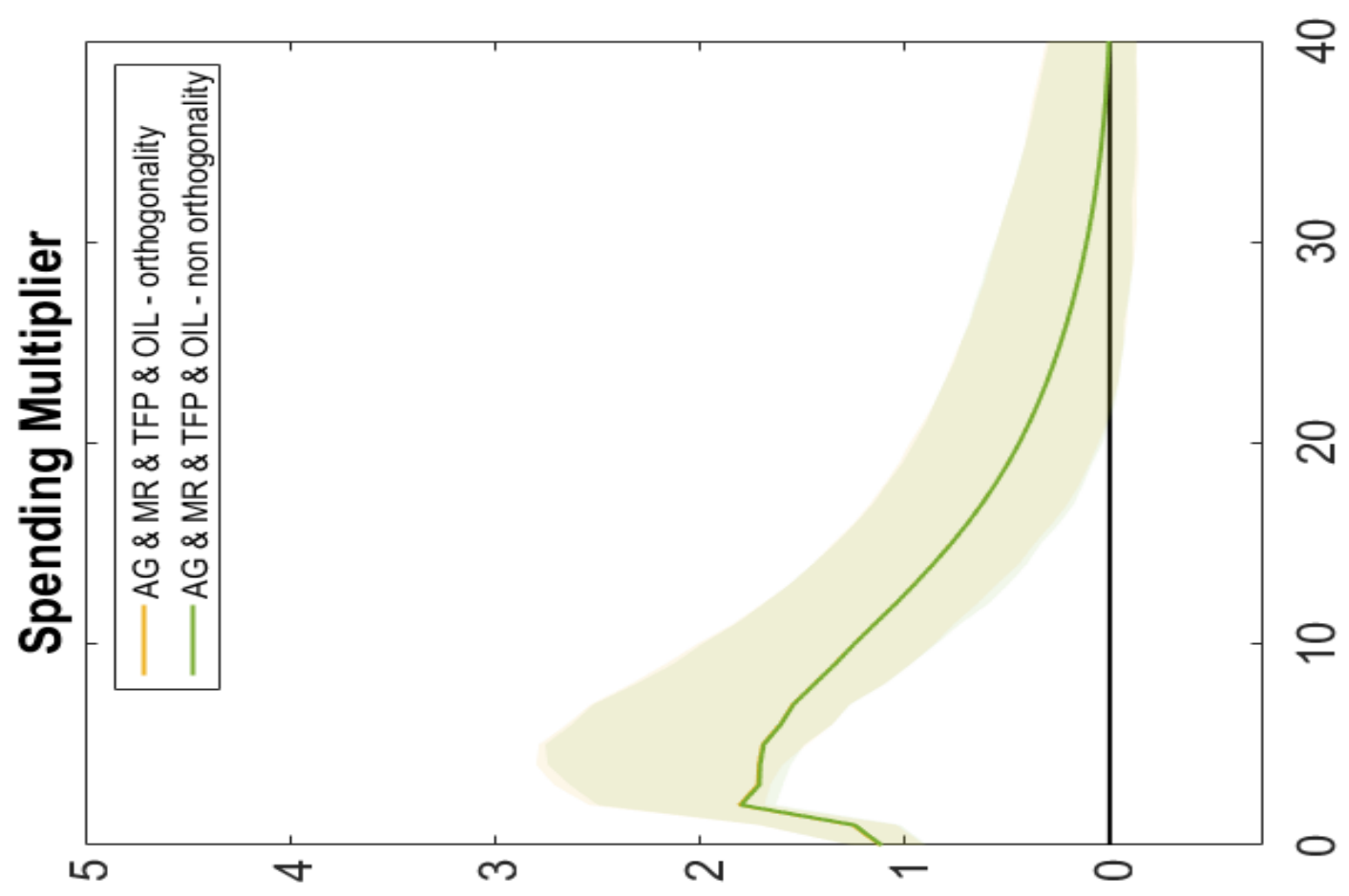

तथ

영 웡

ค.

ㄹ. 이

웡

ํํ유.

$\sum$ चु

青

๙

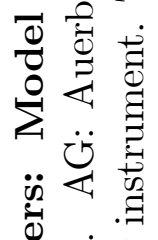

:

壱请

ซี

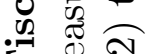

I E

$\ddot{\forall} \in$

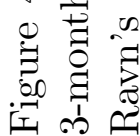




\begin{tabular}{lccc}
\hline \hline \multicolumn{1}{c}{ Instruments } & Shocks & $F_{t}=\left(F_{1, t}\right)$ & $F_{t}=\left(F_{1, t}, F_{2, t}, F_{3, t}, F_{4, t}\right)$ \\
\hline AG only & $\hat{\varepsilon}_{t}^{t r}$ & 0.3612 & 0.2484 \\
& $\hat{\varepsilon}_{t}^{g}$ & 0.8156 & 0.6457 \\
MR only & $\hat{\varepsilon}_{t}^{y}$ & 0.6922 & 0.4343 \\
& $\hat{\varepsilon}_{t}^{t r}$ & 0.1414 & 0.1326 \\
TFP only - orth. & $\hat{\varepsilon}_{t}^{g}$ & 0.8028 & 0.7641 \\
& $\hat{\varepsilon}_{t}^{y}$ & 0.3719 & 0.3248 \\
& $\hat{\varepsilon}_{t}^{t r}$ & 0.3600 & 0.2697 \\
TFP only - non orth. & $\hat{\varepsilon}_{t}^{g}$ & 0.8942 & 0.5046 \\
& $\hat{\varepsilon}_{t}^{y}$ & 0.6843 & 0.4088 \\
AG \& MR \& TFP - orth. & $\hat{\varepsilon}_{t}^{t r}$ & 0.0250 & 0.1128 \\
& $\hat{\varepsilon}_{t}^{g}$ & 0.6242 & 0.3856 \\
AG \& MR \& TFP - non orth. & $\hat{\varepsilon}_{t}^{y}$ & 0.1298 & 0.1983 \\
& $\hat{\varepsilon}_{t}^{t r}$ & 0.4615 & 0.2487 \\
& $\hat{\varepsilon}_{t}^{g}$ & 0.8104 & 0.6452 \\
AG \& MR \& TFP \& OIL - orth. & $\hat{\varepsilon}_{t}^{y}$ & 0.7619 & 0.4432 \\
& $\hat{\varepsilon}_{t}^{t r}$ & 0.1293 & 0.1598 \\
& $\hat{\varepsilon}_{t}^{g}$ & 0.8107 & 0.6451 \\
AG \& MR \& TFP \& OIL - non orth. & $\hat{\varepsilon}_{t}^{y}$ & 0.3808 & 0.3287 \\
& $\hat{\varepsilon}_{t}^{t r}$ & 0.9990 & 0.5354 \\
& $\hat{\varepsilon}_{t}^{g}$ & 0.3827 & 0.3207 \\
& $\hat{\varepsilon}_{t}^{t r}$ & 0.6597 & 0.4623 \\
& $\hat{\varepsilon}_{t}^{g}$ & 0.1289 & 0.3608 \\
\hline \hline
\end{tabular}

Table 2: Informational sufficiency: Forni and Gambetti (2014) test. P-values of F-tests reported in the Table. Per each shock or combination of shocks, we consider two scenarios: a) each fiscal shock regressed over a constant and the estimated factors (first two rows of each shock/combination of shocks); b) the vector of fiscal shocks regressed over constants and the estimated factors ((last row of each shock/combination of shocks). Two lags of the factors included in all cases. 